\title{
NANOCOMPÓSITOS MAGNÉTICOS: POTENCIALIDADES DE APLICAÇÕES EM BIOMEDICINA
}

\author{
Karynne Cristina de Souza e Nelcy Della Santina Mohallem* \\ Departamento de Química, Universidade Federal de Minas Gerais, Av. Pres. Antônio Carlos, 6627, \\ 31270-901 Belo Horizonte - MG, Brasil \\ Edésia Martins Barros de Sousa \\ Centro de Desenvolvimento da Tecnologia Nuclear/Comissão Nacional de Energia Nuclear, \\ Av. Pres. Antônio Carlos, 6627, 31270-901 Belo Horizonte - MG, Brasil
}

Recebido em 21/9/10; aceito em 17/2/11; publicado na web em 5/5/11

\begin{abstract}
MAGNETIC NANOCOMPOSITES: POTENTIAL FOR APPLICATIONS IN BIOMEDICINE. The synthesis of magnetic materials such as nanostructured iron oxide has been intensively researched due to their broad applications in biomedicine. As these nanoparticles have high specific surface area, they are very reactive and can aggregate easily, and biodegrade when exposed to biological systems. Mesoporous silica is often employed as support matrix to protect the magnetic functional component, avoiding undesirable effects. In this context, this review describes various syntheses of silica-coated iron oxide nanoparticles, and their use in applications such as bioseparation, magnetic resonance imaging, hyperthermia and drug delivery systems showing the growing interest of these materials in biological area.
\end{abstract}

Keywords: magnetic nanoparticles; mesoporous silica; bioapplications.

\section{INTRODUÇÃO}

Biomateriais são materiais sintéticos ou naturais usados para substituir partes individuais do organismo ou utilizados em dispositivos médicos que ficam em contato com sistemas biológicos, objetivando o tratamento ou substituição de tecidos individuais, órgãos inteiros ou algumas funções exercidas por eles. ${ }^{1}$ Outras definições incluem: "uma substância sistemática- e farmacologicamente inerte projetada para implantação ou incorporação em sistemas vivos", ou "materiais de origem sintética ou natural em contacto com tecido, sangue e líquidos biológicos e destinados para uso em aplicações protéticas, diagnósticas, terapêuticas e de armazenamento, sem afetar o organismo vivo e seus componentes". Podem também ser definidos como "toda a substância (à exceção de fármacos) ou combinação de substâncias, sintéticas ou naturais, que podem ser usadas por qualquer período de tempo, no conjunto ou como uma parte de um sistema que trate, aumente, ou substitua tecidos, órgãos, ou funções do corpo". ${ }^{2}$

Vários tipos de materiais têm sido objeto de estudo para aplicações biológicas, cujo critério de seleção é baseado principalmente na aplicação a que se destinam. Estes materiais podem ser formados por polímeros sintéticos, metais, cerâmicas, macromoléculas naturais (ex.: biopolímeros) e compósitos que são manufaturados ou processados para se adequarem à utilização em dispositivos médicos que entram em contato íntimo com proteínas, células, tecidos, órgãos e sistemas orgânicos.

A combinação entre cerâmicas e polímeros tem sido muito usada nas últimas duas décadas para produzir compósitos de elevado desempenho. O grande objetivo por trás deste conceito é de se fazer uso de propriedades inerentes das entidades envolvidas, propriedades estas que estão fundamentalmente ligadas à estrutura básica destes materiais (como ligações químicas primárias e arranjo atômico). Dentro deste contexto, os materiais cerâmicos, híbridos cerâmico-

\footnotetext{
*e-mail: nelcy@ufmg.br
}

polímeros e compósitos cerâmico-cerâmicos apresentam grande versatilidade no desenvolvimento de novos materiais com aplicações biotecnológicas. Entretanto, uma das mais importantes características destes materiais é a sua aplicação em escala nanométrica para curar, diagnosticar ou prevenir doenças. A nanotecnologia biomédica, que se baseia na construção de nanopartículas puras ou na combinação de materiais inorgânicos e orgânicos, está assumindo um papel de grande importância para aplicações em diagnóstico, terapêutica, biologia molecular e bioengenharia.

Um dos materiais em destaque para aplicações biomédicas e que tem sido extensamente estudado é a sílica nanoestruturada, cuja química bem estabelecida permite a modificação de sua superfície por vários grupos funcionais como amina, tiol, carboxil e metacrilato. ${ }^{3}$ Este sistema também pode ser modificado com biomoléculas, como enzimas, proteínas e DNA, para aplicações biológicas. A superfície modificada com estas biomoléculas permite o reconhecimento específico entre as espécies livres e as imobilizadas, podendo proporcionar informações diagnósticas ou servir como um processo de separação ou purificação. ${ }^{4}$

Outros materiais que ganham destaque nas aplicações biológicas são as nanopartículas magnéticas. A aplicação de diferentes formas de óxido de ferro para procedimentos diagnósticos como ressonância magnética nuclear (RMN), carreador magnético de drogas e hipertermia magnética tem ganhado ampla aceitação em vários tipos de práticas, embora as aplicações terapêuticas ainda estejam sob investigação. Tais aplicações exploram as duas maiores vantagens dos óxidos de ferro: sua baixa toxicidade em seres humanos e a possibilidade de se controlar sua magnetização. ${ }^{5,6}$

Neste trabalho, apresentamos os métodos de preparação de sílicas porosas utilizadas na confecção de nanocompósitos e as principais sínteses de nanocompósitos formados por óxidos magnéticos dispersos em matriz de sílica, além de suas diversas bioaplicações e efeitos no organismo, evidenciando o crescente interesse do uso destes materiais na área biológica. 


\section{SÍLICA POROSA: XEROGEIS E AEROGEIS}

O processo sol-gel ${ }^{7-15}$ permite a preparação de sílica porosa utilizada como matriz na obtenção de nanocompósitos, incluindo os nanocompósitos magnéticos, com várias aplicações biológicas. Os precursores utilizados no processo sol-gel consistem em alcóxidos metálicos que apresentam ligação do tipo metal-oxigênio-carbono $\left(\mathrm{M}\left(\mathrm{OC}_{\mathrm{n}} \mathrm{O}_{2 \mathrm{n}+1}\right)_{\mathrm{x}}\right)$. A hidrólise de uma solução contendo um alcóxido de silício em um solvente orgânico, como o álcool, leva à formação de partículas com função silanol, as quais formam um sol. A condensação do grupo silanol, $\mathrm{Si}-\mathrm{OH}$, produz ligações $\mathrm{Si}-\mathrm{O}-\mathrm{Si}$ e subprodutos como $\mathrm{H}_{2} \mathrm{O}$ ou $\mathrm{ROH}$, onde $\mathrm{R}$ representa um grupo alquil.

Nesta fase do processo também podem ser adicionados compostos desejados para a obtenção dos compósitos magnéticos, geralmente na forma de nitratos, acetatos, etc. Em seguida é feito o vazamento em um molde onde ocorre a gelificação, que envolve o crescimento e agrupamento de unidades poliméricas para formar uma rede contínua através do líquido. Quando a rede polimérica cresce, devido às reações de condensação, as moléculas se unem para formar macromoléculas que se estendem por toda a solução. Este ponto representa a transição sol para gel. Após a formação do gel, ocorre um processo de mudanças conhecido como envelhecimento, ${ }^{7,16}$ onde as reações químicas que causam a gelificação continuam a ocorrer, produzindo resistência, dureza e contração na rede de sílica. O gel é então submetido à secagem, para a remoção do líquido contido em seus poros, formando o xerogel ou aerogel, dependendo do tipo de secagem utilizada. A diferença principal entre um xerogel e um aerogel está na porosidade destes materiais, que é determinada pelo método de secagem utilizado.

O xerogel é formado a partir da evaporação lenta do solvente, à pressão e temperatura ambientes, o que gera uma maior contração do material e diminuição do tamanho dos poros. $\mathrm{O}$ aerogel é formado a partir da secagem supercrítica, em que o gel úmido é colocado em uma autoclave onde a temperatura e pressão são elevadas acima do ponto crítico do solvente, levando à formação de materiais extremamente porosos..$^{7,17-19} \mathrm{O}$ princípio desta técnica é baseado no fato de que, acima de um ponto crítico de um sistema puro, não existe nenhuma descontinuidade entre a fase líquida e a fase gasosa. Assim, problemas ligados à aparição de forças capilares e interfaciais são eliminados, formando geis secos com grandes porosidades e sem trincas.

A Figura 1 mostra um esquema das diferentes estruturas dos aerogeis e xerogeis. Os aerogeis geralmente possuem grande quantidade de macroporos (diâmetros superiores a $50 \mathrm{~nm}$ ) e apresentam altas áreas superficiais específicas, enquanto que os xerogeis geralmente possuem mesoporos (diâmetros entre 2 e $50 \mathrm{~nm}$ ) ou microporos (diâmetros menores que $2 \mathrm{~nm}$ ) com áreas superficiais específicas menores. ${ }^{19}$
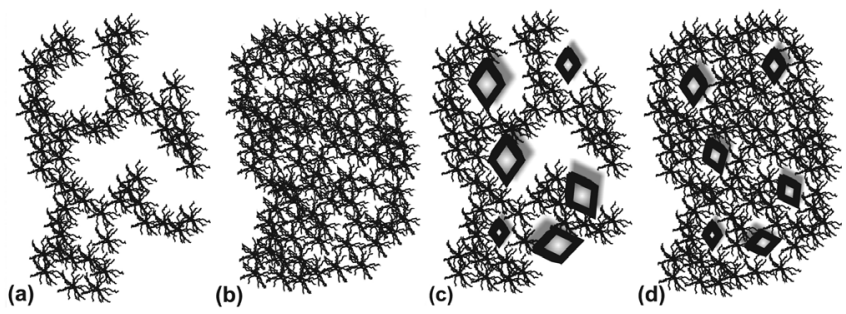

Figura 1. Esquema representativo das estruturas tipo aerogel (a), xerogel (b); em $(c)$ e (d) a representação de um nanocompósito magnético do tipo aerogel e xerogel, respectivamente. Adaptada das refs. 7 e 19

Tanto o xerogel quanto o aerogel possuem grande porosidade e certa quantidade de água e radicais orgânicos. Um tratamento térmico posterior é usado para eliminar radicais indesejáveis e controlar a porosidade, possibilitando o uso do material em temperaturas altas, sem que ocorram mudanças significativas na sua estrutura. ${ }^{7}$

\section{SÍLICA MESOPOROSA ORDENADA}

Em 1992, pesquisadores da Mobil Corporation descobriram a família M41S de peneiras moleculares mesoporosas silicato/aluminossilicato com estruturas de poros uniformes excepcionalmente largos. ${ }^{20,21}$ Estes materiais mesoporosos são preparados através do processo sol-gel ${ }^{22,23}$ em conjunto com agentes direcionadores responsáveis pela arquitetura do esqueleto inorgânico. Dependendo das condições de síntese, da fonte de sílica ou do tipo de surfactante usado, vários tipos de materiais mesoporosos podem ser sintetizados, pelo caminho da auto-organização cooperativa, em que a autoorganização do modelador é seguida da formação da rede mineral, depositada ao redor do substrato auto-organizado. A síntese também pode acontecer mediante formação de cristais líquidos do agente direcionador da estrutura, que serve como molde para o crescimento da rede inorgânica ${ }^{24-26}$ (Figura 2).

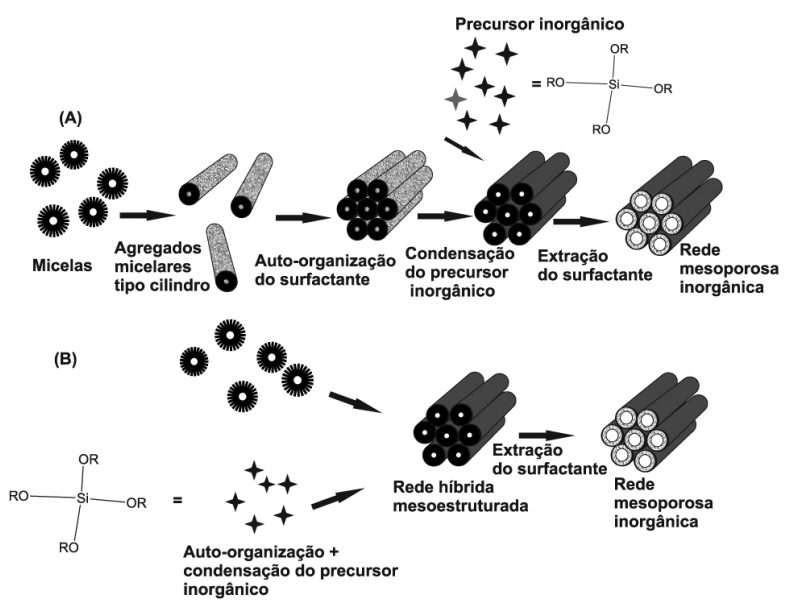

Figura 2. Esquema da formação da estrutura inorgânica mesoporosa mediada por agente direcionador de estrutura: (A) formação de cristal líquido do surfactante e $(B)$ caminho de auto-organização cooperativa. Adaptada das refs. 24 e 25

Os agentes direcionadores podem ser surfactantes moleculares, copolímeros em bloco anfifílicos, dendrímeros ou biomoléculas, que formam organizações micelares e mesofases de cristal líquido. Dependendo do agente direcionador da estrutura usado para síntese e das interações entre as espécies inorgânicas e a molécula do direcionador orgânico (template), os materiais mesoporosos são classificados de acordo com a Tabela 1 .

O principal representante da família dos surfactantes catiônicos é o MCM-41, que significa Mobil Composition of Matter № 41, que apresenta um arranjo hexagonal altamente ordenado de poros unidimensionais, com uma distribuição de tamanho de poros muito estreita e com poros variando de 20 a $100 \AA \AA^{20,21}$ O material representado pela sigla AMS é um exemplo de sílica mesoporosa moldada por surfactante aniônico.

A sílica mesoporosa hexagonal é representada por HMS, e MSU é a sigla para Michigan State University Material. Ambos são formados a partir de interações inorgânica-orgânica não iônica, ou seja, são utilizados surfactantes neutros como aminas primárias (HMS $)^{27}$ e polioxietileno (MSU). ${ }^{28}$ Comparados com o MCM-41, os materiais HMS e MSU apresentam área superficial e volume de poros similares, mas com distribuição de tamanho de poros um pouco mais 
Tabela 1. Possíveis caminhos para a síntese de materiais mesoporosos. Adaptada da ref. 26

\begin{tabular}{|c|c|c|c|c|}
\hline \multirow{2}{*}{$\frac{\text { Template }}{\text { Surfactante iônico }}$} & \multirow{2}{*}{$\frac{\text { Interação }}{\text { Interação direta (Iônica) }}$} & \multicolumn{2}{|c|}{ Condições sintéticas } & \multirow{2}{*}{$\begin{array}{c}\text { Exemplos } \\
\text { MCM-41, MCM-48, MCM-50, FSM-16 }\end{array}$} \\
\hline & & $\mathrm{I}^{-} \mathrm{S}_{\triangle \triangle M \cap \wedge \wedge \wedge}$ & Básico & \\
\hline & & $\mathrm{I}^{+} \mathrm{S}_{\triangle \wedge \wedge \wedge \wedge \wedge \wedge}^{-}$ & Básico-neutro & Alumínio, ferro, óxido de chumbo, AMS \\
\hline & Interação via intermediário (Iônica) & $\mathrm{I}^{+} \mathrm{X}^{-} \mathrm{S}^{+} \wedge \wedge \wedge \wedge \wedge$ & Ácido & SBA-1, SBA-2, SBA-3, \\
\hline & & $\mathrm{I}^{-} \mathrm{X}^{+} \mathrm{S}_{\wedge \wedge \wedge \wedge \wedge}^{-}$ & Básico & Alumínio, óxido de zinco \\
\hline \multirow[t]{2}{*}{ Surfactante não iônico } & Não iônica & $\mathrm{I}^{0} \mathrm{~S}^{0}{ }_{\mathrm{MMAMM}}$ & Ácido & HMS \\
\hline & & $\mathrm{I}^{0} \mathrm{~N}^{0}{ }_{\wedge \wedge \wedge \wedge \wedge \wedge}$ & Ácido & MSU, SBA-15 \\
\hline Copolímero (ligante assistido) & Ligação covalente & $\mathrm{I}-\mathrm{S}_{\triangle \wedge \wedge \wedge}$ & Ácido & Nb-TMS, Ta-TMS \\
\hline Nanomolde & - & - & - & CMK-n \\
\hline
\end{tabular}

I = espécies inorgânicas; $\mathrm{S}$ = surfactante iônico; $\mathrm{N}$ = surfactante não iônico; ${ }^{\wedge \wedge \wedge \wedge \wedge \wedge \wedge \wedge}=$ cadeia orgânica

ampla. A rede mesoporosa de óxido de metal de transição, cuja sigla é TMS, forma ligações covalentes entre os precursores inorgânicos e a molécula de surfactante orgânica, antes da auto-organização.

O processamento de cerâmicas com copolímeros é similar ao de moléculas de surfactante, mas em maior escala de tamanho. Um exemplo é o uso de copolímeros tribloco anfifílicos usados para direcionar a organização de espécies de sílica, resultando em uma rede de mesoporos com estrutura hexagonal e tamanho uniforme de poros de até 300 A. Esses materiais tipo SBA (Santa Barbara Amorphou $^{29}$ ) são sintetizados sob condições ácidas e, subsequentemente, calcinados para formar os mesoporos da estrutura. ${ }^{30}$ Um exemplo típico desses materiais é o SBA-15, que possui um arranjo hexagonal de mesoporos de aproximadamente $6,0 \mathrm{~nm}$ de diâmetro, maior que os poros característicos da estrutura do MCM-41, uma estreita distribuição de tamanho de poros, usualmente na faixa de 4,6 a 30 $\mathrm{nm}$ e áreas superficiais na faixa de $800 \mathrm{~m}^{2} \mathrm{~g}^{-1}$.

\section{BIOCERÂMICAS MAGNÉTICAS E APLICAÇÕES BIOLÓGICAS}

\section{Diagnóstico e biosseparação}

Em 1973, Robinson e colaboradores ${ }^{31,32}$ usaram separação magnética pela primeira vez no contexto biotecnológico. Óxidos de ferro magnéticos revestidos com sílica e, posteriormente, com celulose foram usados para imobilizar duas enzimas: -quimotripsina e -galactosina para aplicações em biorreatores. Desde então, a separação magnética se tornou uma ferramenta cada vez mais comum para separação de moléculas e células.

Jin et al. ${ }^{4}$ modificaram a superfície de partículas de sílica comercial (Aerosil 200 - Degusa-Hüls) com biomoléculas de maleimida, que são muitas vezes empregadas na conjugação de superfícies de biomoléculas que apresentam grupos tióis na superfície. As moléculas de DNA foram imobilizadas, envolvendo: a silanização da superfície do suporte sólido com APTES (aminopropiltrietoxissilano); a reação de ligação cruzada de um ligante heterobifuncional PMPI (isocianato de $p$-maleimidafenil) com o grupo APTES para introduzir uma superfície de maleimida e, a reação de grupos tióis terminais no DNA com a superfície da maleimida. O grupo isocianato do PMPI formou uma ligação tipo ureia com os grupos amina da molécula de APTES. Para ser aplicado em biosseparação, este processo seria mais efetivo se as biomoléculas estivessem ligadas a um suporte magnético formado por um núcleo magnético recoberto com uma superfície altamente funcionalizável. Neste contexto, a sílica parece promissora por causa de sua estabilidade química e física, protegendo as partículas magnéticas em seu interior contra defesas naturais do corpo ou de outros ambientes, além de possuir superfície funcionalizável.
Se a superfície do material magnético for seletiva para uma proteína específica, a proteína será capaz de se ligar a essa superfície e sua separação do meio biológico poderá ser feita pelo uso de um ímã (Figura 3).

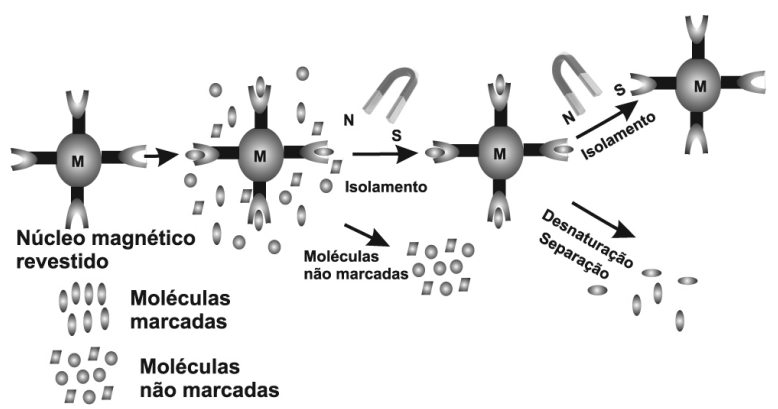

Figura 3. Esquema ilustrando as etapas envolvidas na extração de biomoléculas de uma amostra usando agentes magnéticos de biosseparação (NHAS). Adaptada da ref. 32

O primeiro trabalho de biosseparação em uma superfície de sílica funcionalizada foi realizado por Zhao e colaboradores, em 2003. ${ }^{33}$ Uma coleta e posterior separação de moléculas de DNA/mRNA em uma matriz complexa é criticamente importante no diagnóstico de doenças humanas, estudos de expressão e proliferação de genes. Os autores desenvolveram um novo nanocapturador genomagnético (GMNC) para coleta, separação e detecção de quantidades traço de moléculas de DNA/mRNA que se diferenciam por uma única base. As nanopartículas magnéticas revestidas pela sílica foram sintetizadas pelo método de microemulsão reversa. A microemulsão foi preparada usando $\mathrm{FeCl}_{2}$ e $\mathrm{FeCl}_{3}$ como precursores das nanopartículas de óxido de ferro, tetraetilortossilicato (TEOS) como precursor da camada de sílica e o surfactante Triton X-100. O GMNC é construído pela bioconjugação de moléculas-sonda de DNA na superfície das nanopartículas magnéticas, através da ligação avidina-biotina. O método apresentou excelente habilidade para diferenciar amostras de DNA e mRNA pela combinação da especificidade das moléculas-sonda e posterior separação da molécula de interesse das nanopartículas magnéticas.

Posteriormente, Liu et al. ${ }^{34}$ sintetizaram nanopartículas de magnetita e as recobriram com uma camada de sílica, obtendo esferas de 50 a $80 \mathrm{~nm}$. As nanopartículas de magnetita foram preparadas pelo método de coprecipitação com algumas modificações: $\mathrm{FeCl}_{3} \cdot 6 \mathrm{H}_{2} \mathrm{O}$ e $\mathrm{FeCl}_{2} \cdot 4 \mathrm{H}_{2} \mathrm{O}$ foram dissolvidos em água deionizada em atmosfera de $\mathrm{N}_{2}$ a $90{ }^{\circ} \mathrm{C}$ sob vigorosa agitação. Em seguida, $\mathrm{NH}_{3} \cdot \mathrm{H}_{2} \mathrm{O}$ foi adicionado à solução. O precipitado de coloração preta, característica da magnetita, foi lavado duas vezes com água deionizada por decantação magnética. Silicato de sódio foi dissolvido em água e o valor do $\mathrm{pH}$ 
foi ajustado para 12-13 pela adição de $\mathrm{HCl}$. Essa solução juntamente com as nanopartículas de magnetita foram sonicadas por $30 \mathrm{~min}$ e o precipitado foi lavado com água deionizada várias vezes por decantação magnética. A superfície do compósito foi funcionalizada com um agente de acoplamento amino-silano, $N$-(2-aminoetil)-3-aminopropiltrimetoxissilano (AEAPS). O compósito funcionalizado passou por uma série de experimentos realizados para investigar a imobilização de proteínas nos suportes magnéticos. A albumina bovina (BSA) foi selecionada como proteína modelo e foi imobilizada covalentemente nesse suporte. Para isso, BSA foi dissolvido em uma solução tampão com as nanoesferas com superfície ativada. A mistura foi incubada a $30{ }^{\circ} \mathrm{C}$ por $4 \mathrm{~h}$. Em seguida, o suporte magnético foi separado por um magneto de 2000 Oe. A influência do pH, da força iônica e concentração inicial da proteína na sua imobilização foi estudada. Os resultados mostraram que os compósitos modificados com aminossilano podem ser usados como suporte superparamagnético efetivo e bem disperso para a biosseparação, com capacidade de imobilização máxima de 86 $\mathrm{mg} / \mathrm{g}$ de BSA, apresentando, desta forma, potencial aplicação como suporte imunomagnético para purificação de proteínas.

É possível combinar as vantagens da sílica mesoporosa ordenada e da partícula magnética para fabricar um nanocompósito adsorvente, com alta área superficial específica e boa separabilidade magnética.

Sem et al. ${ }^{35}$ fabricaram nanocompósitos magnéticos à base de sílica mesoporosa e magnetita para aplicação em biosseparação, avaliando a habilidade destes nanocompósitos na ligação e eluição de DNA e na extração de RNA de células bacterianas. As nanopartículas de magnetita foram sintetizadas pelo método de Sugimoto (síntese de oxidação-precipitação), onde uma fonte de $\mathrm{Fe}^{2+}$ é oxidada de forma controlada para $\mathrm{Fe}^{3+}$ até atingir a proporção molar de 1:2 e posterior precipitação da magnetita. As nanopartículas obtidas foram usadas como núcleo para a fabricação do nanocompósito magnético mesoporoso. O surfactante brometo de cetiltrimetilamônio, CTAB, foi usado como direcionador (template) e tetraetilortossilicato (TEOS) como fonte de sílica, em uma síntese típica de obtenção de sílica mesoporosa ordenada. Tanto a magnetita quanto o nanocompósito sílica-magnetita demonstraram alta capacidade de ligação ao DNA. O nanocompósito recobriu quase a totalidade do DNA, enquanto a magnetita recobriu menos de $10 \%$. Foi possível ligar e eluir aproximadamente a mesma quantidade de DNA usando metade da quantidade do compósito mesoporoso ordenado, comparado com materiais à base de magnetita e sílica amorfa clássica. O mecanismo provável de ligação de DNA na superfície do nanocompósito ocorre por meio de interações eletrostáticas entre a cadeia de fosfato carregada negativamente do DNA com a superfície das nanopartículas carregada positivamente no $\mathrm{pH}$ fisiológico.

Já a extração de RNA foi comparável com a obtida com um kit comercial. Além disso, a extração com o nanocompósito mesoporoso não prejudica a qualidade do RNA, mostrando que este tipo de nanocompósito pode ser eficientemente aplicado em biosseparação magnética.

Por causa da baixa carga de enzimas que aderem em esferas magnéticas convencionais, quando estas são utilizadas em imobilização de enzimas, mais atenção tem sido dada aos suportes magnéticos mesoporosos. Um suporte de sílica mesoporosa com magnetita foi sintetizada pela deposição de magnetita e nanopartículas de MCM-41 em gotas de poliestireno usando o método layer-by-layer (LBL). ${ }^{36}$ Este método é baseado na adsorção alternada de polieletrólitos e/ ou espécies inorgânicas com cargas opostas em sistemas coloidais carregados (templates) e posterior remoção do template, levando à formação de semiesferas ocas. A incorporação de magnetita forneceu uma propriedade magnética adicional às esferas de sílica mesoporosa, que resultou na perfeita combinação das propriedades do material mesoporoso com propriedades magnéticas para melhorar a imobilização de enzimas.
Além de diagnóstico e preparação, o uso desses sistemas magnéticos vem se destacando em estudos de liberação controlada de fármacos, que é outro campo de grande interesse na área biológica.

\section{LIBERAÇÃO CONTROLADA DE FÁRMACOS}

A ideia de liberação controlada de substâncias biologicamente ativas começou a ser utilizada na década de 50 com o advento dos materiais poliméricos. As vantagens potenciais de sistemas de liberação controlada incluem: liberação localizada de drogas em um compartimento particular do corpo, diminuindo, dessa forma, o nível sistêmico da droga; manutenção de níveis constantes de droga no organismo, implicando em uma eficiência maior na utilização do agente (ou seja, é necessário menor teor de droga para produzir o mesmo efeito que os sistemas convencionais); preservação dos medicamentos que são rapidamente destruídos pelo corpo (isso é particularmente importante para moléculas biologicamente sensíveis, tais como proteínas) e, menor frequência de administração do agente ativo, aumentando o conforto do paciente e a eficácia do tratamento. ${ }^{37-39}$

Além das matrizes poliméricas, outros sistemas de liberação controlada baseados em diferentes materiais têm sido intensamente estudados nos últimos anos, tais como biocerâmicas e compósitos porosos. Alguns exemplos são antibióticos, tais como gentamicina, liberada a partir de cimentos de fosfato de cálcio ${ }^{40}$ e de compósito hidroxiapatita/colágeno, ${ }^{40}$ norfloxacina e ciprofloxacina, liberados a partir de compósito de hidroxiapatita/colágeno, ${ }^{39}$ e agentes antineoplásicos como cisplatina, liberada a partir de fosfato de cálcio. ${ }^{41}$

Neste contexto, Lien e $\mathrm{Wu}^{42}$ sintetizaram nanopartículas contendo um polímero termossensitivo enxertado na superfície de nanopartículas de $\mathrm{SiO}_{2} / \mathrm{Fe}_{3} \mathrm{O}_{4}$. As nanopartículas monodispersas de magnetita $\left(\mathrm{Fe}_{3} \mathrm{O}_{4}\right)$ de $6 \mathrm{~nm}$ foram sintetizadas através da decomposição térmica de uma mistura de acetilacetonato de ferro (III) e ácido oleico na presença de solventes de alto ponto de ebulição. Essas nanopartículas foram dispersas em cicloexano e revestidas com $\mathrm{SiO}_{2}$ pela técnica de microemulsão reversa, que, por sua vez, foram revestidas pelo polímero PNIPAM (poli $(N-$ isopropilacrilamida)). Um nanocompósito magnético e termossensível com estrutura core-shell foi produzido, com tamanho de partícula de cerca de $30 \mathrm{~nm}$, sendo que cada nanopartícula contém somente um núcleo de $\mathrm{Fe}_{3} \mathrm{O}_{4}$. $\mathrm{O}$ ponto de transição de fase obtido por calorimetria exploratória diferencial (DSC) foi de 34-36 ${ }^{\circ} \mathrm{C}$, que é próximo da temperatura do corpo. Além disso, as nanopartículas mostraram comportamento superparamagnético, apresentando grande potencial como carreadoras de drogas para liberação controlada (DDS/Drug Delivery System).

De acordo com o trabalho de Chen et al. ${ }^{43}$ nanopartículas de $\mathrm{Fe}_{3} \mathrm{O}_{4} / \mathrm{SiO}_{2}$ com estrutura core-shell foram preparadas a partir de uma solução de $\mathrm{Fe}_{3} \mathrm{O}_{4}$ diluído em água e isopropanol, e tetraetilortossilicato coprecipitada com amônia. As nanopartículas magnéticas obtidas foram separadas magneticamente para eliminar núcleos de sílica sem magnetita e, finalmente, foram funcionalizadas com anidrido glutárico e ligadas a um agente anticâncer, a doxorubincina (DOX), via ligação covalente, mais especificamente, uma ligação peptídica entre o grupo amina da DOX e o grupo carboxílico ancorado à superfície do sistema $\mathrm{Fe}_{3} \mathrm{O}_{4} / \mathrm{SiO}_{2}$. Isto possibilitou a estabilidade do sistema carreador, evitando que a droga se soltasse do sistema no processo de transporte..$^{43}$ Nessas condições, a DOX não é liberada da superfície das nanopartículas sob condições intravenosas. A clivagem da ligação amida ocorre a pH baixo e na presença de protease. Neste trabalho, os ensaios de liberação foram feitos em função da variação de $\mathrm{pH}$ e o perfil de liberação da droga mostrou um comportamento pH-dependente. A estrutura core-shell das nanopartículas ligadas à DOX mostrou comportamento superparamagnético, indicando o 
potencial de aplicação no tratamento do câncer usando a tecnologia de liberação de fármacos magneticamente marcados.

A porosidade das matrizes de sílica convencionais é altamente heterogênea, apresentando como grande desvantagem a dificuldade de garantir distribuição homogênea da droga através da matriz, afetando assim a taxa de liberação. Portanto, a necessidade de suprir essa desvantagem tem conduzido a melhoras nesse campo através da utilização de materiais mesoporosos ordenados, que possuem porosidade bem definida. Nanocompósitos formados por nanopartículas magnéticas dispersas em sílica mesoporosa ordenada (SMO), especialmente nanocompósitos de óxido de ferro magnético/SMO ${ }^{44,45}$ permitem elevada incorporação de fármacos/ agentes ativos, bem como a facilidade para marcar seletivamente um tecido ou órgão desejado no corpo através de um campo magnético externo. Esses nanocompósitos, que combinam as vantagens das SMOs e das nanopartículas magnéticas geram um material multifuncional com aplicação na liberação controlada de drogas em sítios específicos.

Souza et al. ${ }^{46}$ sintetizaram nanocompósitos com nanopartículas magnéticas encapsuladas em sílica mesoporosa (SBA-15). O nanocompósito foi preparado em duas etapas: a magnetita foi sintetizada pelo método de oxidação-precipitação e, em seguida, as nanopartículas magnéticas foram revestidas com sílica mesoporosa obtida a partir de tetraetilortossilicato (TEOS) em meio ácido e um surfactante não iônico copolímero em bloco como agente direcionador da estrutura. Souza e colaboradores ${ }^{47}$ estudaram a influência das partículas magnéticas na cinética de liberação de fármacos-modelo: cisplatina, carboplatina e atenolol sob condições in vitro. A liberação foi estudada na ausência e na presença de um campo magnético externo, utilizando um magneto de $\mathrm{NdFeB}$ de $0,25 \mathrm{~T}$. O ensaio de liberação foi realizado também usando um campo alternado em baixas frequências. Para isso, foi projetada e construída uma cavidade magnética, composta de bobina de Helmholtz, que foi conectada a uma fonte de corrente contínua (2) acoplada a um gerador de frequência (1) (Figura 4a) e uma sonda Hall (para medir valor do campo magnético).

O sistema foi construído para gerar um campo magnético uniforme alternado na região central, da ordem de $17 \mathrm{mT}$ e baixas frequências. A frequência da corrente foi variada, fazendo-se um monitoramento com um osciloscópio (3). Foram utilizadas frequências entre 15 e $300 \mathrm{~Hz}$ e um campo magnético de 17 mT. O campo magnético oscilante mostrou uma influência significativa na liberação da cisplatina (Figura 4b), devido, provavelmente, a uma possível interação do fármaco com as nanopartículas de magnetita.

Seguindo a tendência de se buscar métodos de controle da liberação, Zhu et al. ${ }^{48}$ sintetizaram um carreador termorresponsivo usando-se a sílica mesoporosa SBA-15 como matriz suporte para a síntese in situ de partículas magnéticas e posterior polimerização de um polímero termorresponsivo, o poli( $N$-isopropilacrilamida) (PNIPA), nos poros da sílica. A síntese da sílica mesoporosa seguiu uma metodologia bem estabelecida com TEOS como fonte de sílica em meio ácido e um copolímero em bloco anfifílico P123 $\left(\mathrm{EO}_{20} \mathrm{PO}_{70} \mathrm{EO}_{20}\right)$ como agente direcionador de estrutura. $\mathrm{FeCl}_{2}$ foi adicionado lentamente a essa solução sob agitação a $45^{\circ} \mathrm{C}$ por $20 \mathrm{~h}$. Após envelhecimento a $80^{\circ} \mathrm{C}$ por 1 dia, a amostra foi lavada com água, seca à temperatura ambiente e passada por tratamentos térmicos. Este sistema apresentou volume de poros suficiente para encapsular um fármaco modelo, no caso, o ibuprofeno (IBU). O fármaco foi incorporado nos poros desse material e foi realizado um teste de liberação in vitro modulado pela temperatura. A temperatura de transição de fases do gel nesse sistema foi $17^{\circ} \mathrm{C}$ e quando a temperatura estava entre 7 e $11^{\circ} \mathrm{C}$, uma massa de ibuprofeno em torno de $40,5 \%$ foi liberada. À medida que a temperatura aumentou, até alcançar $17^{\circ} \mathrm{C}$, o polímero sofreu contração aumentando ainda mais a taxa de liberação do fármaco.

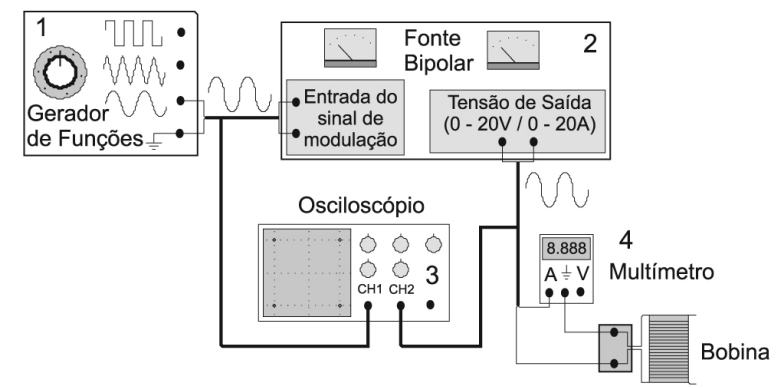

1. Gerador de Funções Hewlet-Packard modelo 3300A

2. Fonte Bipolar Kepco modelo BOP 20-20M

3. Osciloscópio Tektronix modelo TDS 1012B

4. Multímetro Minipa modelo ET 2082B

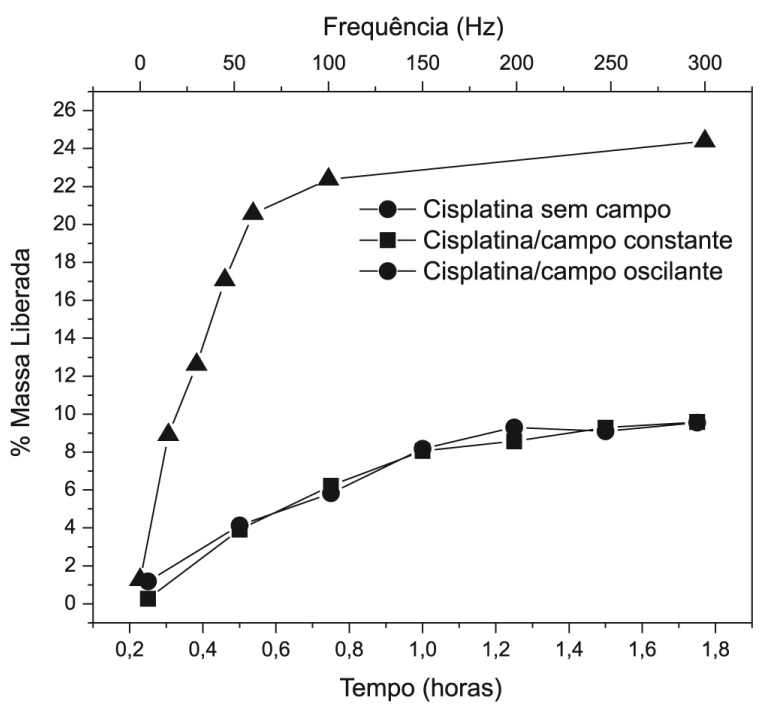

Figura 4. (a) Esquema da instrumentação usada para corrente de 2 A; (b) perfis de liberação do sistema nanocompósito/cisplatina sem campo, com campo fixo e com campo oscilante

Ruiz-Hernández e colaboradores ${ }^{49,50}$ sintetizaram microesferas mesoporosas com nanopartículas magnéticas, através do método de auto-organização induzida por evaporação (EISA - Evaporation Induced Self-assembly), com o objetivo de marcação magnética da matriz em um sítio específico para liberação de drogas in situ. Cloretos de $\mathrm{Fe}^{2+}$ e $\mathrm{Fe}^{3+}$ foram precipitados com hidróxido de amônio, dando origem a partículas de magnetita nanométrica, que foram dispersas em $\mathrm{HNO}_{3}$ e oxidadas à maguemita pela adição de nitrato de ferro, sob aquecimento de $90{ }^{\circ} \mathrm{C}$ por $30 \mathrm{~min}$. O material obtido foi lavado e disperso em água, formando um ferrofluido com partículas de $8 \mathrm{~nm}$, que foi misturado ao surfactante P123 e ao TEOS. Desta solução foi obtido um aerogel que gerou as esferas mesoporosas por pirólise. Do ponto de vista clínico, as microesferas de morfologia homogênea apresentaram vantagens em relação à sílica mesoporosa convencional, cuja síntese leva a um material com morfologia irregular. As microesferas poderiam ser ingeridas e/ou injetadas no paciente. Por outro lado, as propriedades texturais dos materiais mesoporosos ordenados permitiram elevada incorporação da droga e controle da liberação. Contudo, neste trabalho, o tamanho das microesferas sintetizadas foi heterogêneo, com diâmetro variável de 0,3 a $3 \mu \mathrm{m}$, evidenciando um processo de formação de esferas sem um bom controle.

Os sistemas magnéticos apresentam, então, a vantagem de aliar as características de polímeros termossensíveis com o campo magnético externo para permitir uma forma adicional de controle da liberação de fármacos. Outra aplicação bastante promissora para estes materiais 
é como agente de contraste em imagens por ressonância magnética, descrito a seguir.

\section{IMAGENS POR RESSONÂNCIA MAGNÉTICA (IRM)}

As imagens obtidas por ressonância magnética, IRM, possuem alta resolução espacial entre tecidos com diferentes contrastes. Para facilitar o processo de distinção entre os tecidos, foi necessário o desenvolvimento de agentes que aumentassem o contraste entre eles, facilitando o diagnóstico. Alguns agentes de contraste utilizados comercialmente são Feridex $^{\circledR}$, Rosevist $^{\circledR}$, Sinerem $^{\circledR}$, Supravist $^{\circledR}$, que são óxidos de ferro superparamagéticos revestidos com dextran ou carboxidextran. Estes polímeros são hidrofílicos e são utilizados para reduzir a biotoxicidade e aumentar a biocompatilidade. ${ }^{51}$

Nanopartículas baseadas em óxido de ferro têm sido usadas como agentes de contraste em IMR por causa de suas propriedades de encurtamento de $\mathrm{T}_{2} \mathrm{e} \mathrm{T}_{2}{ }^{*}$, que são o tempo de relaxação transversal (spin-spin), referente à componente do vetor magnetização, perpendicular ao campo magnético aplicado, e curto tempo de relaxação transversal, respectivamente. Em um procedimento para IRM, quando o núcleo atômico absorve energia pelas ondas de rádio aplicadas externamente, libera esta energia como um sinal, ao retornar ao seu estado de menor energia. A taxa com a qual um núcleo volta ao seu estado de energia mais baixa é chamada de relaxação. As nanopartículas distorcem o campo magnético local e alteram $\mathrm{T}_{2}$ e $\mathrm{T}_{2}{ }^{*}$ dos prótons da água nas moléculas de água da vizinhança. Essa propriedade faz com que sirvam como um agente de contraste negativo em IRM para aplicações biológicas. ${ }^{52}$ Duas classes de partículas são consideradas:

i) partículas volumosas (> $30 \mathrm{~nm}$ de volume hidrodinâmico - tamanho global compreendendo o revestimento orgânico e moléculas de água), chamadas de partículas de óxidos de ferro superparamagnéticos (SPIOs - Superparamagnetic Iron Oxides), usadas para imagens IRM do fígado. Elas apresentam meia-vida curta $\left(\mathrm{T}_{1 / 2}\right)$, que é o tempo característico para a eliminação de material estranho no sangue pelo sistema retículo endotelial (RES), que existe no fígado, baço e linfonodos. Este tempo é uma das propriedades mais importantes para aplicações de agentes de contraste para IMR; $;^{50}$

ii) partículas menores ( $<30 \mathrm{~nm}$ de diâmetro hidrodinâmico), chamadas de ultrapequenas SPIOs (USPIOs), que apresentam longo $\mathrm{T}_{1 / 2}$, sendo usadas, por exemplo, para angiografia por ressonância magnética (angio-RM) e imagens IRM de macrófagos e linfonodos, bem como agentes de marcação celular. ${ }^{53,54}$ As USPIOs têm um menor contraste negativo que as SPIOs, devido à baixa relaxação de $\mathrm{T}_{2} \cdot{ }^{51}$

No caso de óxidos de ferro revestidos com polímeros orgânicos, como mostrado na Tabela 2, $\mathrm{T}_{1 / 2}$ aumenta com o decréscimo do diâmetro da partícula e com revestimento polimérico não iônico. Agentes com um longo $\mathrm{T}_{1 / 2}$, tais como um USPIO, que têm pequeno diâmetro hidrofílico abaixo de $50 \mathrm{~nm}$, podem ser usados como agentes de contraste para hemorragias e para imageamento de macrófagos, em comparação com o agente fígado-específico Ferumoxides (Feridex) com seu curto $\mathrm{T}_{1 / 2}$ com SPIO, que tem tamanho de partícula acima de $50 \mathrm{~nm}$.

Revestimentos com sílica ou por glicolação com polietileno conferem estabilidade adicional e biocompatibilidade às nanopartículas de óxido de ferro. Além disso, corantes orgânicos incorporados na camada de sílica permitem a detecção das nanopartículas por fluorescência através de microscopia confocal de varredura a laser (Confocal Laser Scanning Microscopy - CLSM). ${ }^{52}$

Recentemente, nanopartículas de óxido de ferro revestidas com sílica e PEG, com propriedades magnéticas e fluorescentes, foram desenvolvidas e aplicadas para marcação celular e classificação de células, com vantagem multimodal em IMR e microscopia por fluorescência para uso in vivo e ex vivo. ${ }^{55-57}$

Lee et al ${ }^{51}$ desenvolveram um material consistindo de nanopartículas magnéticas e fluorescentes revestidas com sílica onde incorporaram isotiocianato de rodamina B (RITC). As nanopartículas foram preparadas por coprecipitação de soluções aquosas de $\mathrm{CoCl}_{2}-\mathrm{FeCl}_{3}$ em meio alcalino, e foi empregado um método de revestimento da sílica baseado no uso de polivinilpirrolidona (PVP). O PVP é usado quando as partículas possuem cargas iônicas na sua superfície para gerar um revestimento de sílica pelo processo sol-gel, com espessura variando de acordo com a quantidade de tetraetoxissilano (TEOS) usado. As nanopartículas magnéticas e fluorescentes revestidas com sílica (denominadas de MFSNs) tiveram sua superfície modificada com polietilenoglicol (PEG) para torná-las biocompatíveis e solúveis em água. As MFSNs apresentaram o mesmo tamanho das SPIOs (70 $\mathrm{nm}$ ) e apresentaram alto valor de relaxação, porém, longa meia-vida $\left(\mathrm{T}_{1 / 2}\right)$ de $\sim 2,5 \mathrm{~h}$ (Tabela 2), similar à das USPIOs, sendo o primeiro trabalho que mostrou uma longa circulação de SPIOs com um grande tamanho hidrofílico e uma longa meia-vida no sangue, característica de USPIOs. Essa propriedade surge da modificação da superfície com revestimento de sílica e PEG, que é conhecido como um inibidor contra a captação pelo fígado. ${ }^{58}$

Trabalho semelhante foi realizado por Sung e colaboradores em $2009^{59}$ (Tabela 3), que avaliaram a marcação de células-tronco mesenquimais humanas (hMSCs) com nanopartículas magnéticas de ferrita de cobalto bifuncionais para IRM e CLSM, com o objetivo de monitoramento de transplante das mesmas. Estas nanopartículas, de tamanho médio de cerca de $9 \mathrm{~nm}$, foram sintetizadas por coprecipitação a partir de uma solução contendo $\mathrm{FeCl}_{3} \cdot 6 \mathrm{H}_{2} \mathrm{O}$ e $\mathrm{CoCl}_{2} \cdot 6 \mathrm{H}_{2} \mathrm{O}$, em uma solução aquecida de $\mathrm{NaOH}$ e estabilizadas com PVP. O TEOS foi polimerizado na superfície das nanopartículas. RITC foi incorporado no sistema e, por último, a superfície da sílica foi modificada com PEG para evitar uma adsorção não específica de proteínas às nanopartículas, formando um compósito dual funcionalizado (NPM@ $\mathrm{SiO}_{2}$ (RITC)-PEG).

A integração da sílica mesoporosa com nanocristais superparamagnéticos monodispersos para formar compósitos core-shell

Tabela 2. Propriedades primárias de nanopartículas de óxido de ferro. Adaptada da ref. 54

\begin{tabular}{lccccc}
\hline Nomes & Tamanho hidrodinâmico (nm) & Agente de revestimento & $\mathrm{T}_{1 / 2}$ em humanos (h) & $\mathrm{T}_{1 / 2}$ em ratos (h) & Aplicações \\
\hline $\begin{array}{l}\text { Feridex }{ }^{\circledR} \\
\text { Resovist }^{\circledR}\end{array}$ & $120-180$ & Dextran & 2 & 0,1 & IMR de fígado; marcação celular \\
Sinerem $^{\circledR}$ & 60 & Carboxidextran & $2,4-3,6$ & - & $\begin{array}{c}\text { IMR de fígado; marcação celular } \\
\text { IMR de linfonodos metastáticos; IMR } \\
\text { Supravist }\end{array}$ \\
MFSN & $15-30$ & Dextran & $24-36$ & $1,4-3$ & $\begin{array}{c}\text { de macrófagos; agente de contraste para } \\
\text { hemorragias; marcação celular }\end{array}$ \\
& 21 & Carboxidextran & 6 & - & $\begin{array}{c}\text { Agente de contraste para hemorragias; } \\
\text { marcação celular }\end{array}$ \\
\hline
\end{tabular}


Tabela 3. Características de NPM@ $\mathrm{SiO}_{2}(\mathrm{RITC})-\mathrm{PEG}$

\begin{tabular}{|c|c|c|}
\hline $\mathrm{NPM} @ \mathrm{SiO}_{2}(\mathrm{RITC})-\mathrm{PEG}$ & Ref. 51 & Ref. 59 \\
\hline Recobrimento & PEG & PEG \\
\hline Núcleo & Nanopartículas de ferrita de cobalto $\left(\mathrm{CoFe}_{2} \mathrm{O}_{4}\right)^{60}$ & Nanopartículas de ferrita de cobalto $\left(\mathrm{CoFe}_{2} \mathrm{O}_{4}\right)^{55}$ \\
\hline Diâmetro do núcleo & $38 \mathrm{~nm}$ & $15 \mathrm{~nm}$ \\
\hline Diâmetro da partícula & $70 \mathrm{~nm}$ & $50 \mathrm{~nm}$ \\
\hline Corante fluorescente & Rodamina B & Rodamina B \\
\hline Estudo & Imagens por RMN e teste preliminar de fluorescência & Imagens por RMN e CLSM \\
\hline
\end{tabular}

uniformes tem mostrado grande potencial para bioimagem. ${ }^{60}$ Nesse contexto, Lin et al. ${ }^{61}$ e Kim et al..$^{62}$ desenvolveram nanopartículas de sílica mesoporosa magnética/luminescente por rotas similares. Foram sintetizadas nanopartículas monodispersas menores que 100 nm usando nanocristais de $\mathrm{Fe}_{3} \mathrm{O}_{4}$ como núcleos magnéticos (designadas como $\mathrm{Fe}_{3} \mathrm{O}_{4} @ \mathrm{mSiO}_{2}$ ). Em ambos os casos, $\mathrm{CTAB}$ (brometo de cetiltrimetilamônio) foi usado como agente modelador da estrutura inorgânica para a formação da sílica mesoporosa ordenada. Em seguida, os nanocompósitos foram funcionalizados com corantes e/ou PEG que foram usados primeiro para marcar células de fibroblatos NIH 3 T3 e células MCF-7 e, segundo, para estudo in vivo de IRM e imagem fluorescente em camundongos. No primeiro trabalho (Lin et $a l$.), foi demonstrado que o nanocompósito era capaz de internalizar células NIH 3T3 sem precisar de qualquer outra técnica de reforço. No segundo trabalho (Kim et al.), as células MCF-7 marcadas com $\mathrm{Fe}_{3} \mathrm{O}_{4} @ \mathrm{mSiO}_{2}$ (corante)-PEG e células MCF-7 controle, sem marcação, foram injetadas subcutaneamente em cada lado do dorso de um rato. As células marcadas foram claramente detectadas nas imagens ponderadas por $\mathrm{T}_{2}$. Ainda nesse trabalho, imagens de fluorescência foram obtidas e, para isso, dois corantes isotiocianato de fluoresceína (FITC) e isotiocianato de rodamina B (RITC) foram ligados covalentemente na parede da sílica (Tabela 4).

\section{Marcação tumoral}

Administração intravenosa (IV) é o método mais efetivo para liberar agentes de contraste para estudar órgãos e tecidos, pois todas as células vitais recebem suprimentos por meio da circulação san- guínea. ${ }^{63}$ Além disso, permite a liberação controlada de um fármaco adequado ao tratamento de órgãos doentes em local específico.

Para marcação de tumores com nanopartículas magnéticas (NPs), um aspecto importante que tem que ser levado em conta é a limitação de tamanho das nanopartículas para sistemas injetáveis. A maioria dos sítios é acessível através da microcirculação pelos capilares sanguíneos ou através de poros presentes em várias superfícies e membranas. A maioria das aberturas a níveis celulares e subcelulares é de tamanho nanométrico (Tabela 5); então, com o uso de nanopartículas é possível alcançar o nível subcelular.

Do ponto de vista da condução de drogas no organismo, não existe nenhuma limitação prática quando o diâmetro de NPs típicas tem uma dimensão menor do que o diâmetro da secção cruzada do capilar mais estreito, que é cerca de $2 \mu \mathrm{m}$. Na realidade, para um transporte eficiente as nanopartículas deveriam ser menores que $300 \mathrm{~nm} .{ }^{64,65}$

Um dos requisitos de qualquer sistema de liberação é sua habilidade para se movimentar livremente no sistema circulatório e atravessar várias barreiras que podem estar no caminho. No corpo humano, a maioria das passagens são os vasos sanguíneos através dos quais os materiais são transportados no corpo. Mas apenas o movimento nos vasos não supre o objetivo da condução de drogas. O sistema de liberação necessita alcançar o sítio no nível desejado. Isso requer atravessar as paredes dos capilares para alcançar o fluido extracelular do tecido e então atravessar outras células, se elas estão no caminho, e alcançar as células-alvo. Essas são as maiores barreiras no percurso. ${ }^{65}$

No caso de tumores, esse transporte é facilitado devido ao extravasamento das NPs no local doente, pois a microvasculatura é hiperpermeável e a drenagem linfática do tumor é limitada. Isso leva

Tabela 4. Características de $\mathrm{Fe}_{3} \mathrm{O}_{4} @ \mathrm{mSiO}_{2}$ (corante)-PEG

\begin{tabular}{lcc}
\hline $\mathrm{Fe}_{3} \mathrm{O}_{4} @ \mathrm{mSiO}_{2}$ & Ref. 62 & Ref. 61 \\
Recobrimento & PEG & - \\
Núcleo & Nanopartículas de $\mathrm{Fe}_{3} \mathrm{O}_{4}$ & $\mathrm{Nanopartículas} \mathrm{de} \mathrm{Fe}_{3} \mathrm{O}_{4}$ \\
Diâmetro do núcleo & 15 e $22 \mathrm{~nm}$ & - \\
Diâmetro da partícula & 53 e $45 \mathrm{~nm}$ & FITC-APTMS* \\
Corante fluorescente & FITC e RITC & Imagens por RMN e CLSM \\
Estudo & Imagens por RMN e imagem fluorescente
\end{tabular}

* N-1-(3-trimethoxy-silylpropyl)- $N$-fluoresceyl thiourea

Tabela 5. Tamanho de poros versus distribuição de partículas nos capilares do sistema vascular humano. Adaptada da ref. 64

\begin{tabular}{|c|c|c|c|}
\hline & & Tamanho & Sistema/Órgão \\
\hline a) No sistema circulatório & $\begin{array}{l}\text { Raio de arteríolas } \\
\text { Raio de artérias } \\
\text { Raio de veias }\end{array}$ & $\begin{array}{c}0,005-0,07 \mathrm{~mm} \\
0,08-7,5 \mathrm{~mm} \\
8-100 \mu \mathrm{m}\end{array}$ & $\begin{array}{l}\text { Sistema circulatório. Partículas fornecidas por administração } \\
\text { intravenosa. A eliminação envolve opsonização e remoção por } \\
\text { monócitos no sangue. }\end{array}$ \\
\hline $\begin{array}{l}\text { b) Permeabilidade } \\
\text { das nanopartículas }\end{array}$ & $\begin{array}{l}\text { Capilares de junção estreita } \\
\text { Capilares contínuos } \\
\text { Capilares fenestrados } \\
\text { Capilares sinusoidais }\end{array}$ & $\begin{aligned} & <1 \mathrm{~nm} \\
& \sim 6 \mathrm{~nm} \\
\sim & 50-60 \mathrm{~nm} \\
\sim & 100-1000 \mathrm{~nm}\end{aligned}$ & $\begin{array}{c}\text { Sistema nervoso central, barreira sangue-cérebro } \\
\text { Tecidos tais como músculo, pele e pulmão } \\
\text { Rins, intestino e algumas glândulas endócrinas e exócrinas } \\
\text { Fígado, baço e medula óssea }\end{array}$ \\
\hline
\end{tabular}


a uma acumulação seletiva das NPs no tecido tumoral, num processo conhecido como marcação passiva. ${ }^{64}$

A permeabilidade da parede é um fator crítico para liberação de agentes por administração intravenosa. Pelo fato da rápida liberação de moléculas ou partículas no sangue para o interstício dos tecidos ser baseada na difusão, o tamanho dos poros que fazem o revestimento do capilar endotelial regula a permeabilidade dos agentes. A estrutura dos capilares é diferente em diferentes órgãos e classificada em quatro tipos (Figura 5, Tabela 5). ${ }^{63}$ No sistema nervoso central, por causa do revestimento endotelial ser conectado firmemente por uma junção íntima (Barreira Hematoencefálica - BHE), mesmo um pequeno agente de contraste molecular não difunde para o espaço extravascular (Figura 5a). Esses agentes então podem ser chamados de agentes de marcação específica para o sistema nervoso central, pois nos tecidos patológicos faltam BHE e o agente de contraste pode ser acumulado e distinguido dos tecidos normais vizinhos.
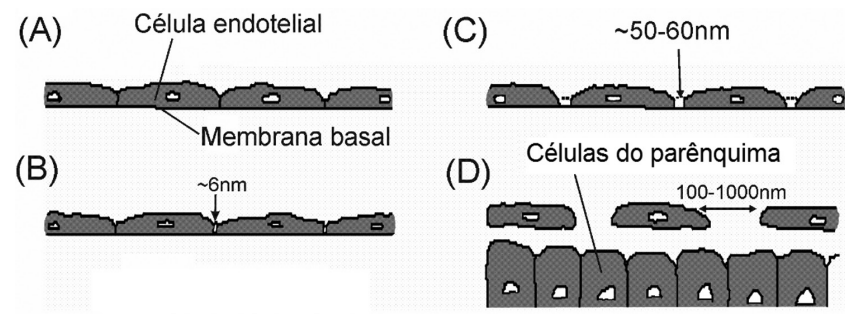

Figura 5. Ilustração esquemática de diferentes classes de capilares sanguíneos: (a) capilares de junção estreita do sistema nervoso central; (b) capilares contínuos incluindo a maioria dos tecidos, tais como, músculo, pulmão e pele; (c) capilares fenestrados, incluindo rins, intestino e algumas glândulas endócrinas e exócrinas; (d) capilares sinusoidais, incluindo fígado, baço e medula óssea. Adaptada da ref. 63

A maioria dos tecidos, tais como músculo, pele, pulmão e tecido conjuntivo apresentam capilares contínuos (Figura 5b). Partículas com um tamanho variando de 5 a $50 \mathrm{~nm}$ não podem difundir livremente nesses tecidos e são excretadas pelos rins que têm capilares fenestrados (Figura 5c), por excreção urinária. É claro que os efeitos do tamanho molecular na permeabilidade são complicados por diferenças na carga e configuração. Um agente de contraste neste intervalo pode ser específico para tecidos hemorrágicos e patológicos, pois os agentes são retidos no sangue por tempo suficiente para a produção da imagem de uma hemorragia contrastada e serem liberados passivamente para tecidos patológicos, cujos capilares são geralmente mais permeáveis. O tamanho mínimo de agentes macromoleculares para um tamanho de poros de aproximadamente $6 \mathrm{~nm}$ é $\sim 20 \mathrm{kDa}$ para partículas de forma globular e $50 \mathrm{kDa}$ para partículas de forma linear.

Partículas de dezenas de nanômetros podem somente ser removidas pelo sistema retículo endotelial, tais como células de Kupffer no fígado e macrófagos no baço, medula óssea e linfonodos, pois esses capilares são sinusoidais e têm centenas de nanômetros de poros (Figura 5d). Baseada nessa estrutura de capilar, a liberação seletiva para o RES representado pelo fígado é alcançada por um dimensionamento preferencial. A magnetita revestida com dextran, por exemplo, no grupo das SPIOs, tem um tamanho médio de $80 \mathrm{~nm}$ e tem sido clinicamente provado que ela é um agente de contraste específico para o fígado. ${ }^{63}$

Os sistemas SPIOs e USPIOs, além de possibilitarem a marcação de tecidos alvo que servem como agentes de contraste, podem ser guiados até um sítio específico pela aplicação de um campo magnético externo e lá serem aquecidos pela aplicação de um campo magnético oscilante, num processo conhecido como hipertermia magnética, discutido a seguir.

\section{HIPERTERMIA}

Hipócrates (460-370 a.C.) acreditava que qualquer doença poderia ser curada pelo aquecimento do corpo do paciente. ${ }^{66}$ Dentro desta filosofia, desde 1957 a hipertermia, ${ }^{67-70}$ uma modalidade de tratamento de câncer com elevação de temperatura entre 41 e $45^{\circ} \mathrm{C}$ com um tempo de tratamento de no mínimo $30 \mathrm{~min}$, tem ganhado considerável atenção devido a sua eficácia clínica, tal como minimizar efeitos locais clínicos e a possibilidade de destruir seletivamente tumores malignos localizados ou profundamente enraizados. ${ }^{67}$

As células cancerosas geralmente perecem em torno de $43{ }^{\circ} \mathrm{C}$, pois sua fonte de oxigênio via vasos sanguíneos fica insuficiente nesta temperatura, enquanto células normais não são danificadas na mesma temperatura. Além disso, os tumores são mais facilmente aquecidos do que os tecidos normais vizinhos, já que os vasos sanguíneos e o sistema nervoso são pobremente desenvolvidos no tumor. Desta forma, a hipertermia é um tratamento de câncer útil com poucos efeitos locais. Várias técnicas para aquecimento dos tumores, tais como tratamento com água quente, radiação infravermelha, ultrassom e micro-ondas, têm sido testadas. Entretanto, tumores localizados em partes profundas do corpo não são efetivamente aquecidos usando-se essas técnicas. ${ }^{68}$

Alguns pesquisadores propuseram o conceito de hipertermia intracelular, utilizando partículas magnéticas de tamanho submicrométrico para induzir a hipertermia. Esse conceito é baseado no fato de que sob um campo magnético alternado (AMF - Alternating Magnetic Field), partículas magnéticas podem gerar calor.

Existem no mínimo três mecanismos diferentes pelos quais materiais magnéticos podem gerar calor em um campo oscilante: ${ }^{69}$ (i) circulação de correntes parasitas induzidas no material; (ii) perda de energia por histerese em materiais de multidomínio e, (iii) perda de energia por relaxação em materiais magnéticos superparamagnéticos de monodomínio.

Os mecanismos (i) e (ii) contribuem muito pouco para o aquecimento de partículas com regime de monodomínio. Então, o mecanismo significante que contribui para o aquecimento dessas partículas é o mecanismo de relaxação (iii). A perda de energia por relaxação em nanopartículas magnéticas de monodomínio acontece de dois modos: modo rotacional (de Brown) e modo de Néel. O princípio de geração de calor devido a cada modo individual é mostrado na Figura 6 (b e c). No modo de Néel, o momento magnético inicialmente bloqueado ao longo do eixo de fácil magnetização do cristal rotaciona em direção ao campo externo. O mecanismo de Néel é análogo à perda de energia por histerese em partículas magnéticas de multidomínio, já que existe uma "fricção interna" devido ao movimento do momento magnético em um campo magnético externo que resulta na geração de calor. No modo Browniano, a geração de calor se dá através da oscilação das partículas como um todo em direção ao do campo magnético externo, sob o efeito de uma força térmica, contra a viscosidade em uma suspensão. Esse mecanismo representa essencialmente o componente de fricção mecânica das nanopartículas em uma suspensão.

Em 1979, Gordon e colaboradores ${ }^{66}$ propuseram o conceito de indução de hipertermia intracelular usando nanopartículas de magnetita ligadas ao dextran. Administraram nanopartículas de magnetita intravenosamente em carcinoma mamário de ratos e mostraram que houve indução de calor por AMF em seus experimentos.

Kawashita e colaboradores ${ }^{68}$ estudaram microesferas de magnetita com capacidade de produzir calor, principalmente em tumores localizados nas partes profundas do corpo. Dois tipos de microesferas foram sintetizados: de magnetita e de sílica/magnetita. No primeiro caso, as microesferas de magnetita foram obtidas pela fusão de um pó puro de $\mathrm{Fe}_{3} \mathrm{O}_{4}$ e posterior resfriamento à temperatura ambiente. Em um processo de indução de aquecimento por radiofrequência a 

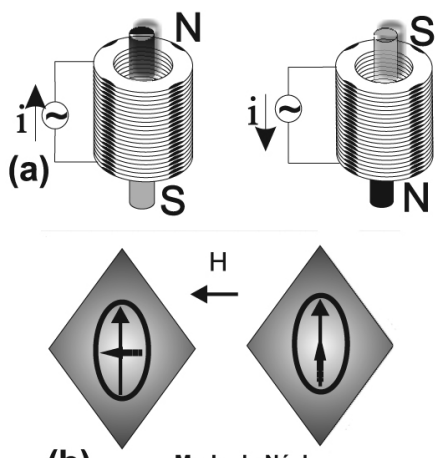

(b) Modo de Néel

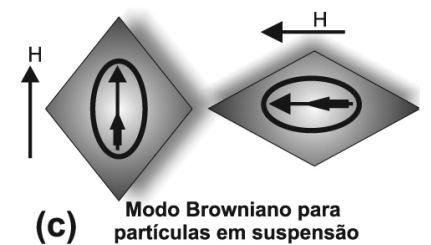

(c) partículas em suspensão

Figura 6. (a) Esquema da indução de campo para material magnético em uma bobina de corrente alternada; (b) e (c) perda de energia por relaxação, levando ao aquecimento em um campo magnético oscilante: (b) modo de Néel; (c) modo de relaxação Browniano. Adaptada da ref. 69

uma potência de 19,0 kW e uma frequência de 4 MHz, o gás argônio produziu um plasma de temperatura entre 12.000 a $13.000^{\circ} \mathrm{C}$. O pó de magnetita foi transportado por um fluxo de argônio até a chama de plasma para ser fundido na temperatura do plasma. Posteriormente, o material fundido foi gotejado em água extrapura à temperatura ambiente, que estava localizada na base de uma câmara de $1 \mathrm{~m}$ de altura. No segundo caso, pós de $\mathrm{Fe}_{3} \mathrm{O}_{4}$ foram adicionados a uma solução aquosa de ácido fluorídrico e agitados a $30{ }^{\circ} \mathrm{C}$ por $24 \mathrm{~h} . \mathrm{O}$ excesso de $\mathrm{Fe}_{3} \mathrm{O}_{4}$ foi filtrado para produzir uma solução de $\mathrm{HF}$ a $1 \%$ (p/p) contendo $\mathrm{Fe}_{3} \mathrm{O}_{4}$ a uma concentração saturada (Fe-HF solução). Microesferas de sílica vítrea de $12,4 \mu \mathrm{m}$ de diâmetro foram mergulhadas na solução obtida por vários períodos até 24 dias para favorecer a precipitação de $\beta-\mathrm{FeOOH}$ na sua superfície . Os produtos obtidos foram aquecidos a várias temperaturas entre 300 e $600{ }^{\circ} \mathrm{C}$ por $1 \mathrm{~h} \mathrm{e}$, então, resfriados em uma atmosfera de $70 \%$ de $\mathrm{CO}_{2}+30 \%$ de $\mathrm{H}_{2}$ para obtenção de magnetita. $\mathrm{O}$ diâmetro das microesferas de magnetita foi de 20 a $30 \mu \mathrm{m}$, com capacidade para geração de $10 \mathrm{~W} / \mathrm{g}$ a 300 Oe e $100 \mathrm{kHz}$; as microesferas de sílica vítrea recobertas com magnetita apresentaram tamanho médio de $25 \mu \mathrm{m}$, enquanto que o tamanho de cristalitos de magnetita depositados na superfície foi estimado em 50 $\mathrm{nm}$. No último caso, a geração de calor foi de $41 \mathrm{~W} / \mathrm{g}$ nas mesmas condições, mostrando que o sistema microesfera de sílica/magnetita é um sistema promissor para tratamento hipertérmico de câncer.

Existe uma segunda possível aplicação para este sistema, a liberação controlada de drogas, que pode ser desencadeada por ação termomagnética, ajustando-se o campo magnético e a frequência. Com esse pensamento, Hu et al. ${ }^{71}$ estudaram nanoesferas de sílica magnético-sensíveis para liberar o fármaco ibuprofeno de forma instantânea e controlada em uma concentração terapeuticamente efetiva por meio de um campo magnético de alta frequência (HFMF - High Frequency Magnetic Field). As nanoesferas foram sintetizadas por um processo in situ, onde a sílica foi preparada pelo método sol-gel, em meio ácido. À solução precursora das nanoesferas foi misturada uma solução de $\mathrm{Fe}\left(\mathrm{NO}_{3}\right)_{3} \cdot 9 \mathrm{H}_{2} \mathrm{O}$ (usado como precursor para a fase magnética) em diferentes razões molares de $\mathrm{Si}: \mathrm{Fe}$, seguida pela adição de ibuprofeno, obtendo-se, assim, nanoesferas com tamanho de partículas de cerca de $50 \mathrm{~nm}$, ideais para liberar quantidades específicas de droga em uma maneira "explosiva" via exposição curta a um HFMF.
Ao acelerar a rotação de nanopartículas magnéticas depositadas na matriz de sílica gerando energia na forma de calor, o HFMF leva ao alargamento da nanoestrutura da matriz de sílica produzindo canais porosos que fazem a droga ser facilmente liberada. Dessa forma, as nanoesferas apresentaram um perfil de liberação acentuada de ibuprofeno nos intervalos de 180 a 190 min de liberação, em que o sistema foi exposto por 10 min em HFMF. Esse perfil foi comparado com um grupo controle que não foi exposto ao campo magnético. Foi medido também o perfil de liberação cumulativo de ibuprofeno a partir das nanoesferas na razão $\mathrm{Si}: \mathrm{Fe}=1: 1$ sem estímulo magnético e com estímulo magnético de $50 \mathrm{kHz}$, aplicado por 4 intervalos específicos de tempo, mostrando que após a excitação magnética houve um aumento significativo da quantidade de fármaco liberada em cada intervalo.

Recentemente, Julian-Lopez et $a .^{72}$ realizaram um estudo de sistemas sílica mesoporosa/partículas magnéticas em hipertermia magnética. As nanopartículas de maguemita, obtidas com um tamanho médio de $8 \mathrm{~nm}$, resultaram da oxidação da magnetita estequiométrica (sintetizada pelo método de coprecipitação), através de seu tratamento com uma solução de ácido perclórico. Estas partículas foram recobertas com sílica mesoporosa pelo método spray-drying, dando origem a microesferas do tipo SBA-15/maguemita e MCM41/maguemita. Além disso, funcionalizaram a superfície destes materiais para serem usados no transporte de moléculas bioativas em aplicações biomédicas. O efeito do aquecimento deste sistema após aplicação de um campo magnético oscilante de frequência 180 $\mathrm{kHz}$ e $70 \mathrm{kAm}^{-1}$ (879,65 Oe) foi comparado com o efeito de nanopartículas de maguemita dispersas em solução aquosa, nas mesmas condições. Seu desempenho apresentou menor eficiência do que as nanopartículas dispersas em água, mas ainda assim, o novo sistema é uma fonte efetiva de aquecimento.

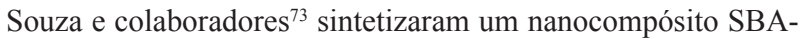
15/nanopartículas de magnetita, impregnando a sílica mesoporosa com uma solução contendo $\mathrm{Fe}_{3}\left(\mathrm{SO}_{4}\right)_{3}$. Após um tratamento térmico a $550{ }^{\circ} \mathrm{C}$ por $2 \mathrm{~h}$ em atmosfera ambiente foi obtido um sistema que, por autorredução a $550{ }^{\circ} \mathrm{C}$ por $8 \mathrm{~h}$ em atmosfera inerte $\left(\mathrm{N}_{2}\right)$, gerou o nanocompósito SBA-15/ $\mathrm{Fe}_{3} \mathrm{O}_{4}$. Foram realizados dois ensaios de hipertermia magnética, onde o nanocompósito se mostrou bastante promissor para o uso nesta aplicação (Figura 7).

No primeiro caso (Figura 7a) observa-se uma variação de temperatura $(\Delta \mathrm{T})$ de $21{ }^{\circ} \mathrm{C}$ para o nanocompósito submetido a 168 Oe e $\Delta \mathrm{T}$ de apenas $3{ }^{\circ} \mathrm{C}$ a $105 \mathrm{Oe}$, mostrando que o aquecimento depende da intensidade do campo magnético. O segundo caso (Figura 7b) mostra que o meio de dispersão das nanopartículas também influencia no aquecimento. A amostra sonicada apresentou uma variação bem maior de temperatura $\left(\Delta \mathrm{T}=23^{\circ} \mathrm{C}\right)$ no tempo de $20 \mathrm{~min}$ do que a amostra dispersa em água pura $\left(\Delta \mathrm{T}=5^{\circ} \mathrm{C}\right)$.

\section{METABOLISMO DAS NANOPARTÍCULAS}

\section{Nanopartículas magnéticas}

Nanopartículas magnéticas (SPIOs) $)^{50}$ permanecem em circulação no sangue por períodos de tempo que dependem do tamanho da partícula e da superfície de revestimento das mesmas. Isso porque essas partículas são capturadas pelo sistema retículo endotelial - SER (atualmente conhecido como sistema fagocítico mononuclear), que consiste principalmente de macrófagos e que está presente no fígado, baço, linfonodos e medula óssea. ${ }^{74}$ Os macrófagos são vitais para a coordenação da resposta imune, eliminação de patógenos e controle da homeostase dos tecidos. Os macrófagos também têm um papel importante na reciclagem do ferro presente no corpo. Devido ao alto nível de expressão de proteínas específicas em estocar o ferro, os 

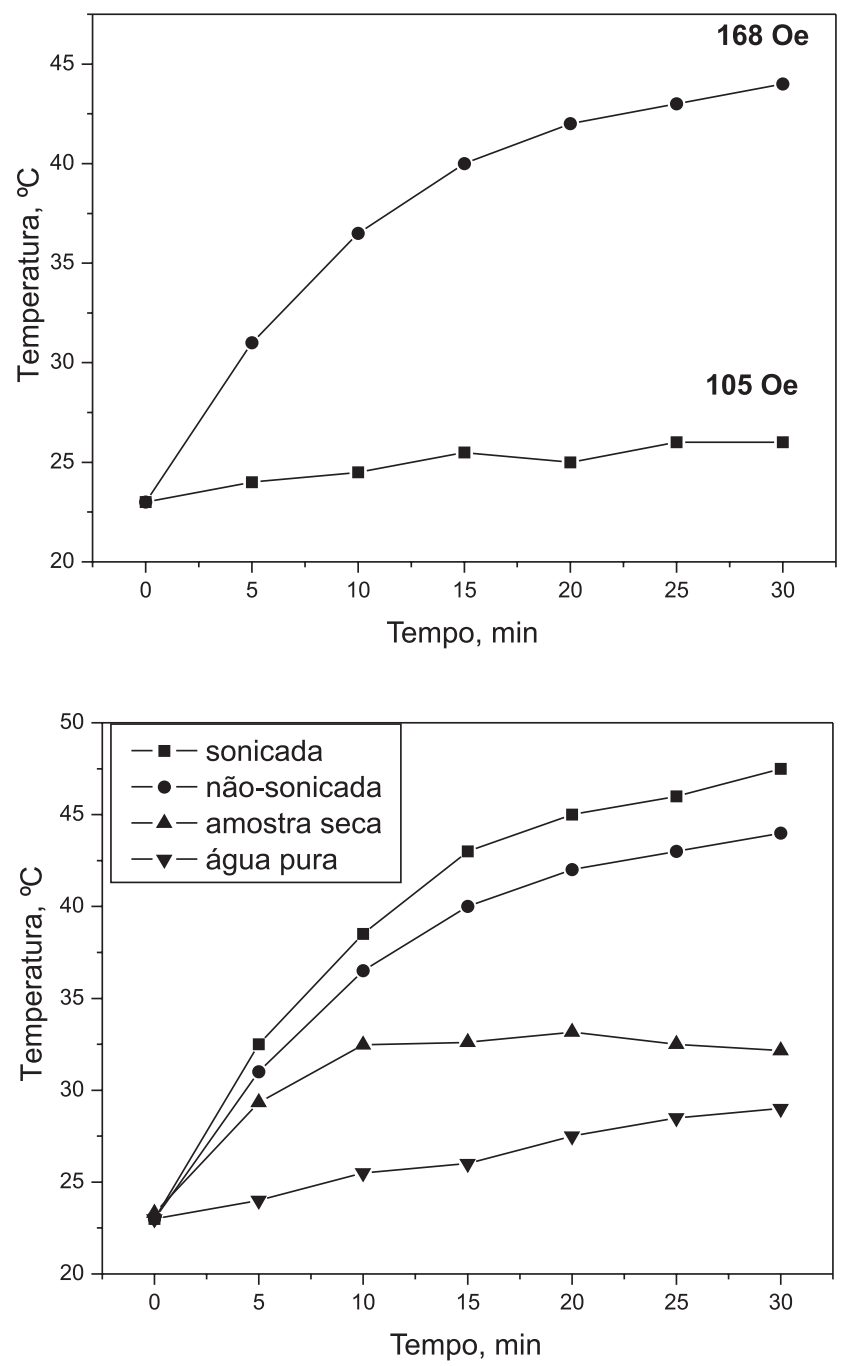

Figura 7. (a) Ensaio de hipertermia magnética para dispersão aquosa do nanocompósito a 198 kHz e campos magnéticos de 168 e 105 Oe; (b) aquecimento induzido por campo magnético do nanocompósito em diferentes situações a 168 Oe comparado com a água pura, usada como controle

macrófagos podem sustentar uma carga de ferro relativamente alta. ${ }^{75}$

Uma vez injetadas no organismo, as nanopartículas são rapidamente capturadas pelos macrófagos circulantes ou residentes e internalizados em seus lisossomos. No caminho da endocitose celular, as nanopartículas passam por um contínuo decréscimo do $\mathrm{pH}$, desde o meio extracelular $(\mathrm{pH}=7-7,5)$, passando pelo endossomo intracelular $(\mathrm{pH}=5,5-6)$, até atingir o microambiente ácido dos lisossomos $(\mathrm{pH}$ $=4,5-4,8)$. A membrana lisossomal permite que enzimas digestivas trabalhem no $\mathrm{pH}$ 4,5 de que necessitam, bombeando prótons do citosol. As nanopartículas confinadas nos lisossomos são então expostas a efeitos combinados de $\mathrm{pH}$ ácido, hidrolases lipossomais e, eventualmente, quelantes de ferro envolvidos na regulação do ferro. ${ }^{76}$ Devido ao $\mathrm{pH}$ fisiológico normal e ao oxigênio encontrado no plasma, o estado de oxidação preferencial do ferro é a forma férrica. Qualquer íon ferroso presente no plasma será rapidamente oxidado pelo oxigênio molecular endógeno, resultando na conversão de íon ferroso em férrico. Apesar do $\mathrm{Fe}^{3+}$ ser o estado de oxidação fisiológico preferencial do ferro, ele é altamente reativo e pode induzir atividade catalítica, resultando em severos danos celulares. Como resultado, proteínas e quelantes carreadores de ferro são usados para permitir sua segura transferência através das células e para garantir o estoque intracelular do excesso de ferro. Nos vertebrados, a transferrina é a responsável pelo transporte seguro do ferro e a ferritina está envolvida no seu estoque. Ambas as proteínas se ligam fortemente ao ferro, limitando sua reatividade e reduzindo a formação de produtos hidrolíticos, que podem causar dano celular. Além disso, a ligação do ferro nessas proteínas é reversível, de modo que ele pode ser obtido quando necessário em processos metabólicos, síntese de enzimas e proteínas e/ou produção de heme. ${ }^{77}$

Devido a essa condição biológica peculiar do ferro, nanopartículas de óxido de ferro são menos tóxicas do que outros nanocristais inorgânicos e têm a chance de ser transformadas pela homeostase celular. Sabe-se que os diferentes macrófagos não utilizam o mesmo tipo de reconhecimento de moléculas, por exemplo, macrófagos primários humanos não apresentaram nenhum efeito imunomodulatório quando as células foram expostas a nanopartículas de óxido de ferro revestidas com dextran $(30 \mathrm{~nm})$, mas os macrófagos peritoneais apresentaram secreção de citocinas anti-inflamatórias e redução na produção de citocinas pró-inflamatórias quando expostos a nanopartículas também revestidas com dextran $(20 \mathrm{a} 60 \mathrm{~nm}){ }^{78}$

Raynal et al. ${ }^{79}$ reportaram que a absorção de SPIOs revestidas com dextran $(100 \mathrm{~nm})$ pelos macrófagos peritoneais de ratos foi mediada via endocitose dependente de receptores (scavenger receptor-classe A (SR-A)). Partículas menores revestidas com dextran (20 nm) foram inicialmente absorvidas por pinocitose. As SPIOs internalizadas via caminho endocítico foram, então, sequestradas nos lisossomos. Essa absorção foi posteriormente influenciada por proteínas presentes no plasma que envolveram (opsonização) as nanopartículas de óxido de ferro.

Experimentos de biodistribuição demonstraram uma acumulação de 55\% da dose de SPIOs revestidas com ácido oleico/surfactante (tamanho médio de $190 \mathrm{~nm}$ ), injetadas intravenosamente em fígados de ratos, devido à eliminação das SPIOs pelo sistema mononuclear fagocitário. A eliminação via urina e fezes de aproximadamente $25 \%$ de SPIOs revestidas com dextran (tamanho médio de $80 \mathrm{~nm}$ ) ocorreu em 19 dias em ratos, mas em outros modelos de animais, a eliminação de sistemas semelhantes ocorreu em 7 semanas. ${ }^{78}$

Esses estudos mostram a importância de se usar diferentes sistemas celulares para o estudo toxicológico, uma vez que a absorção celular pode acontecer por diferentes caminhos, dependendo das propriedades das nanopartículas e do tipo específico de célula em questão.

\section{Sílica porosa}

O silício é abundante nos tecidos conjuntivos, cabelos, peles, tendões, músculos e ossos, sendo que espécies de silício livres dissolvidas na forma de ácido monossilícico podem difundir através do tecido celular em torno de um implante, entrar na corrente sanguínea ou linfa e, então, serem excretadas na urina. A sílica pode ser biodegradada em ácidos silícicos incluindo ácidos silícicos monoméricos e poliméricos. Os ácidos polissilícicos podem causar citotoxidade via adsorção e ligação a enzimas e proteínas, enquanto o monomérico não se liga a proteínas, não provocando citotoxidade. ${ }^{80-82}$

No caso de uma permanência da matriz de sílica a longo prazo in vivo, porções insolúveis poderão se acumular e necessitam ser removidas cirurgicamente. Desta forma, é essencial a investigação do comportamento de degradação destes materiais. ${ }^{80}$

He et al. ${ }^{80}$ mostraram os estudos de vários pesquisadores sobre a dissolução de matrizes de sílica derivadas do processo sol-gel, e concluíram que essa dissolução se passa em duas etapas: erosão da superfície seguida pela lenta degradação do material. Aparentemente, as matrizes de sílica derivadas do processo sol-gel, sílicas mesoporosas ordenadas e vidros mesoporosos bioativos mostram taxas de degradação da ordem de dias a meses. ${ }^{81-84}$ Viitala et al.$^{84}$ estudaram a degradação da sílica cujo tempo variou de 4 dias (para os monólitos) 
a aproximadamente 80 dias (para as micropartículas). Por outro lado, He et al. ${ }^{80}$ observaram uma degradação in vitro extraordinariamente rápida $(2 \mathrm{~h})$ de sílica mesoporosa obtida a partir de tetraetilortossilicato, quando imerso em SBF (Fluido Corpóreo Simulado) à temperatura de $37^{\circ} \mathrm{C}$.

Em estudos in vitro com células de diferentes tipos, a absorção celular das nanopartículas mesoporosas se mostrou dependente do tamanho, ${ }^{85}$ de sua carga superficial específica e do tipo celular. ${ }^{86,87}$ Nanopartículas de sílica mesoporosa com um tamanho de $50 \mathrm{~nm}$ acumularam-se na região perinuclear de células de carcinoma cervical. Kunzmann et al. ${ }^{78}$ demonstraram que partículas mesoporosas foram capturadas pelos macrófagos primários humanos derivados de monócitos via processo ativo e a absorção celular foi independente da presença de plasma no meio de cultura, sugerindo que as partículas não opsonizadas estavam sendo reconhecidas pela células. Esses materiais foram, portanto, considerados não tóxicos para os macrófagos.

He et al. ${ }^{88}$ fizeram um estudo da localização intracelular e da toxicidade de nano e micropartículas de sílica esférica mesoporosa, avaliando a influência do tamanho e concentração das matrizes, que forneceu evidências diretas da indução de dano ao lisossomo e morte celular. Os efeitos dos produtos da biodegradação, o surfactante residual e a remoção do surfactante por extração e calcinação na toxicidade também foram analisados. As partículas mesoporosas esféricas foram sintetizadas com três tamanhos diferentes (190, 420 e $1220 \mathrm{~nm}$ de diâmetro) para investigar sua toxicidade em células humanas de câncer de mama e células de rins de macaco africano. Os produtos de biodegradação das partículas esféricas não mostraram nenhuma toxicidade para as células sob um amplo intervalo de concentrações e todas as amostras investigadas mostraram baixa toxicidade. $\mathrm{O}$ surfactante residual $\mathrm{CTAB}$, vinculado às partículas, apresentou uma contribuição muito menor à toxicidade do que o surfactante livre. A toxicidade foi correlacionada ao tamanho das partículas: partículas na nanoescala mostraram significante toxicidade a concentrações acima de $25 \mathrm{mg} \mathrm{mL}^{-1}$, enquanto micropartículas mostraram ligeira toxicidade sobre o amplo intervalo de concentrações de 10 a $480 \mathrm{mg} \mathrm{mL}^{-1}$.

Em trabalho recente, Hudson et al. ${ }^{81}$ testaram injeções subcutâneas de três tipos diferentes de sílica mesoporosa em ratos, observando que a quantidade residual dos materiais decresceu progressivamente após 3 meses, com boa biocompatibilidade e nenhuma toxidade. Em contraste, injeções intraperitoneais e intravenosas em camundongos levaram à morte ou sofrimento dos animais, necessitando de eutanásia. Assim, apesar da reação local ter sido benigna, os materiais causaram severa toxicidade sistêmica, pelo menos com a administração de doses muito elevadas ( $30 \mathrm{mg}$ por rato). Os estudos in vitro mostraram graus de toxicidade variáveis para os diferentes tipos de sílica mesoporosa em diferentes linhagens de células. As partículas sem surfactante foram altamente tóxicas para todas as três linhas de células testadas, presumivelmente devido ao surfactante catiônico residual presente nos poros, enquanto que o tamanho das partículas, neste caso, não apresentou influência significativa na toxicidade, cujo tamanho variou de $150-4000 \mathrm{~nm}$.

\section{COMENTÁRIOS FINAIS}

O encapsulamento de nanopartículas magnéticas por sílica mesoporosa amorfa ou ordenada melhora sua dispersão, aumenta sua estabilidade química em meio biológico e reduz a toxicidade. Além disso, a sílica apresenta grupos silanois em sua superfície que podem facilmente ser funcionalizados, servindo como matriz suporte para incorporar diversas moléculas de interesse farmacológico para uso na área biomédica, em diagnóstico e terapia.

Entretanto, apesar das significativas vantagens, já demonstradas, das propriedades destes nanocompósitos, os estudos envolvendo o uso destes materiais ainda estão no início, já que alguns procedimentos de síntese ainda estão sendo modificados para aumentar o controle sobre sua morfologia e estrutura e, desta forma, melhorar seu desempenho em utilizações comerciais.

Estudos toxicológicos também estão sendo realizados, embora os resultados ainda pareçam conflitantes devido aos tipos de metodologias utilizadas. É muito importante estudar principalmente os efeitos de nanopartículas no organismo, magnéticas ou não, que são materiais muito reativos, e o efeito da degradação da sílica no organismo.

\section{AGRADECIMENTOS}

Ao CNPq e à FAPEMIG pelo apoio financeiro.

\section{REFERÊNCIAS}

1. William, D. F.; The William Dictionary of Biomaterials, Liverpool, 1999. apud Dorozhkin, S. V.; Glass and Ceramics 2007, 64, 11.

2. Park, J. B.; Bronzino, J. D.; Biomaterials: principles and applications, CRC PRESS: Boca Raton, 2002

3. Smith, J. E.; Wang, L.; Tan, W. T.; TrAC, Trends Anal. Chem. 2006, 25, 848.

4. Jin, L.; Horgan, A.; Levicky, R.; Langmuir 2003, 19, 6968.

5. Chastellain, M.; Petri, A.; Gupta, A.; Rao, K. V.; Hofmann, H.; Adv. Eng. Mater. 2004, 6, 235.

6. Răcuciu, M.; Analele Stiintifice ale Universitatii "Al. I. Cuza” iasi Tomul II, s. Biofizică, Fizică medicală şi Fizica mediului 2006, 67.

7. Brinker, C. J.; Scherer, G. W.; Sol-Gel Science: The Physics and Chemistry of Sol-Gel Processing, Academic Pess Inc.: New York, 1990.

8. Hiratsuka, R. S.; Santilli, C. V.; Pulcinelli, S. H.; Quim. Nova 1995, 18, 171.

9. Miranda, L. A.; Mohallem N. D. S.; Magalhães W. F.; Appl. Surf. Sci. 2006, 253, 3466.

10. Dislich, H.; Angew. Chem., Int. Ed. 1971, 10, 363.

11. Brinker, C. J.; Scherer, G. W.; Roth, E. P.; J. Non-Cryst. Solids 1985, 72, 301.

12. Murherjee, S. P.; J. Non-Cryst. Solids 1982, 48, 177.

13. Dislich, H.; Hinz, P.; Thin Solids Films 1982, 48, 11.

14. Sakka, S.; Kamiya, K.; J. Non-Cryst. Solids 1982, 48, 31.

15. Alfaya, A. A. S.; Kubota, L. T.; Quim. Nova 2002, 25, 835.

16. Panjonk, G. M.; Venkateswara, A.; Sawant, B. M.; J. Non-Cryst. Solids 1997, 209, 40.

17. Schneider, M.; Baiker, A.; Catal. Rev. - Sci. Eng. 1995, 37, 515.

18. Silva, J. B.; Diniz, C. F.; Viana, A. P. P.; Mohallem, N. D. S.; J. Sol-Gel Sci. Technol. 2005, 35, 115.

19. Silva, J. B.; Mohallem, N. D. S.; J. Sol-Gel Sci. Technol. 2010, 55, 15.

20. Beck, J. S.; Vartuli, J. C.; Roth, W. J.; Leonowicz, M. E.; Kresge, C. T.; Schmitt, K. D.; Chu, C. T-W.; Oslon, D. H.; Sheppard, E. W.; McCullen, S. B.; Higgins, J. B.; Schlenkert, J. L.; J. Am. Chem. Soc. 1992, 114, 10834.

21. Kresge, C. T.; Leonowicz, M. E.; Roth, W. J.; Vartuli, J. C.; Beck, J. S.; Nature 1992, 359, 710.

22. Chen, L. Y.; Ping, Z.; Chuah, G. K.; Jaenicke, S.; Simon G.; Microporous Mesoporous Mater. 1999, 27, 231.

23. Choi, D. G.; Yang, S. M.; J. Colloid Interface Sci. 2003, 261, 127.

24. Soler-Illia, G. J. A. A.; Sanchez, C.; Lebeau, B.; Patarin, J.; Chem. Rev. 2002, 102, 4093 .

25. Raman, N. K.; Anderson, M. T.; Brinker, C. J.; Chem. Mater. 1996, 8 , 1682 .

26. Taguchi, A.; Schüth, F.; Microporous Mesoporous Mater. 2005, 77, 1.

27. Tanev, P. T.; Pinnavaia, T. J.; Science 1995, 267, 865.

28. Boissière, C.; van der Lee, A.; El Mansouri, A.; Larbot, A.; Prouzet, E.; Chem. Commun. 1999, 2047. 
29. Jung, J. S.; Choi, K. H.; Jung, Y. K.; Lee, S. H.; Golub, V. O.; Malkinski L.; O'Connor, C. J.; J. Magn. Magn. Mater. 2004, 272-276, 1157.

30. Zhao, D.; Feng, J.; Huo, Q.; Melosh, N.; Fredrickson, G. H.; Chmelka, B. F.; Stucky, G. D.; Science 1998, 279, 548.

31. Bruce, I. J.; Taylor, J.; Todd, M.; Davies, M. J.; Borioni, E.; Sangregorio, C.; Sem, T.; J. Magn. Magn. Mater. 2004, 284, 145.

32. De, M.; Ghosh, P. S.; Rotello, V. M.; Adv. Mater. 2008, 20, 4225.

33. Zhao, X. J.; Tapec-Dytioco, R.; Wang, K. M.; Tan, W. H.; Anal. Chem. 2003, 75, 3476.

34. Liu, X.; Xing, J.; Guan, Y.; Guobin, S.; Liu, H.; Colloids Surf., A 2004, $238,127$.

35. Sen, T.; Sebastianelli, A.; Bruce, I. J.; J. Am. Chem. Soc. 2006, 128, 7130.

36. Xie, T.; Wang, A.; Huang, L.; Li, H.; Chen, Z. ; Wang, Q.; Yin, X.; African J. Biotechnol. 2009, 8, 4724.

37. Langer R.; Science 1990, 249, 1527.

38. Ogawa, C. A.; Plepis, A. M. G.; Polímeros: Ciência e Tecnologia 2002, 12,115 .

39. Baro, M.; Sánchez, E.; Delgado, A.; Perera, A.; Évora, C.; J. Controlled Release 2002, 83, 353.

40. Martins, V. C. A.; Goissis, G.; Artificial Organs 2000, 24, 224.

41. Barroug, A.; Kuhn, L. T.; Gerstenfeld, L. C.; Glimcher, M. J.; J. Orthop. Reserc. 2004, 22, 703.

42. Lien, Y. H.; Wu, T. M.; J. Colloid Interface Sci. 2008, 326, 517.

43. Chen, F. H.; Gao, Q.; Ni, J. Z.; Nanotechnology 2008, 19, 165103.

44. Wang, Y. G.; Ren, J. W.; Liu, X. H.; Wang, Y. Q.; Guo, Y.; Guo, Y. L.; Lu, G. Z.; J. Colloid Interface Sci. 2008, 326, 158.

45. Huang, S. S.; Yang, P. P.; Cheng, Z. Y., Li, C.; Fan, Y.; Kong, D.; Lin, J.; J. Phys. Chem. C 2008, 112, 7130.

46. Souza, K. C.; Salazar-Alvarez, G.; Ardisson, J. D.; Macedo, W. A. A.; Sousa, E. M. B.; Nanotechnology 2008, 19, 185603.

47. Souza, K. C.; Ardisson, J. D.; Sousa, E. M. B.; J. Mater. Sci.: Mater Med. 2009, 20, 507.

48. Zhu, S.; Zhou, Z.; Zhang, D.; Jin, C.; Li, Z.; Microporous Mesoporous Mater. 2007, 106, 56.

49. Ruiz-Hernandez, E.; Lopez-Noriega, A.; Arcos, D., Izquierdo-Barba, I.; Terasaki, O.; Vallet-Regí, M.; Chem. Mater. 2007, 19, 3455.

50. Ruiz-Hernandez, E.; López-Noriega, A.; Arcos, D.; Vallet-Regí, M.; Sol. State Sci. 2008, 10, 421.

51. Lee, K.; Cheong, C.; Hong, K. S.; Koh, E. K.; Kim, M.; Shin, H. S.; Kim, Y-N.; Lee, S. H.; J. Korean Phys. Soc. 2008, 53, 2535.

52. Lee, K.; Park, C.; Moona, H-Y.; Ahn, E.; Park, H. E.; Ihm, S-H.; Seung, K-B.; Yoon, T-J.; Chang, K.; Lee, C.; Cheong, C.; Hong, K. S.; Curr. Appl. Phys. 2009, 9, S12.

53. Lawaczeck, R.; Menzel, M.; Pietsch, H.; Appl. Organomet. Chem. 2004 $18,506$.

54. Corot, C.; Robert, P.; Idée, J. M.; Port, M.; Adv. Drug Delivery Rev. 2006, 58, 1471.

55. Yoon, T. J.; Kim, J. S.; Kim, B. G.; Yu, K. N.; Cho, M. H.; Lee, J. K.; Angew. Chem., Int. Ed. 2005, 44, 1068.

56. Kim, J. S.; Yoon, T.-J.; Yu, K.-N.; Noh, M. S.; Woo, M.; Kim, B.-G.; Lee, K.-H.; Sohn, B.-H.; Park, S.-B.; Lee, J.-K.; Cho, M.-H.; J. Veterinary Sci. 2006, 7, 321

57. Lu, C. W.; Hung, Y.; Hsiao, J.-K.; Yao, M.; Chung, T.-H.; Lin, Y.-S.; Wu, S.-H.; Hsu, S.-C.; Liu, H.-M.; Mou, C.-Y.; Yang, C.-S.; Huang, D.-M.; Chen, Y.-C.; Nano Lett. 2007, 7, 149.

58. Lukyanov, A. N.; Sawant, R. M.; Hartner, W. C.; Torchilin, V. P.; J. Biomater. Sci. 2004, 15, 621.
59. Sung, C. K.; Hong, K. A.; Lin, S.; Lee, Y.; Cha, J.; Lee, J-K; Hong, C. P.; Han, B. S.; Jung, S. I.; Kim, S. H.; Yoon, K. S.; Korean J. Radiology 2009, 10, 613 .

60. Sousa, M. H.; Tourinho, F. A.; Depeyrot, J.; Silva, G. J.; Lara, M. C. F. L.; J. Phys. Chem. B 2001, 105, 1168.

61. Lin, Y. S.; Wu, S. H.; Hung, Y.; Chou, Y. H.; Chang, C.; Lin, M. L.; Tsai, C. P.; Mou, C. Y.; Chem. Mater. 2006, 18, 5170.

62. Kim, J.; Kim, H. S.; Lee, N.; Kim, T.; Kim, H.; Yu, T.; Song, I. C.; Moon, W. K.; Hyeon, T.; Angew. Chem., Int. Ed. 2008, 47, 8438.

63. Okuhata, Y.; Adv. Drug Delivery Rev. 1999, 37, 121.

64. Arruebo, M.; Galan, M.; Navascues, N.; Tellez, C.; Marquina, C.; Ibarra, M. R. Santamaria, J.; Chem. Mater. 2006, 18, 1911.

65. Gupta, R. B.; Kompella, U. B.; Nanoparticle Technology for Drug Delivery, Ed. Taylor \& Francis: New York, 2006, vol. 159.

66. Ito, A.; Shinkai, M.; Honda, H.; Kobayashi, T.; J. Biosci. Bioeng. 2005, $100,1$.

67. Bae, S.; Lee, S. W.; Hirukawa, A.; Takemura, Y.; Jo, Y. H.; Lee, S. G.; IEEE Transactions on Nanotechnology 2009, 8, 86

68. Kawashita, M.; Tanaka, M.; Kokubo, T.; Inoue, Y.; Yao, T.; Hamada, S.; Shinjo, T.; Biomaterials 2005, 26, 2231.

69. Kalambur, V. S.; Han, B.; Hammer, B. E.; Shield, T. W.; Bischof, J. C.; Nanotechnology 2005, 16, 1221.

70. Hergt, R.; Andra, W.; d'Ambly, C. G.; Hilger, I.; Kaiser, W. A.; Richter, U.; Schmidt, H. G.; IEEE Trans. on Magn. 1998, 34, 3745.

71. Hu, S. H.; Liu, T. Y.; Huang, H. Y.; Liu, D. M.; Chen, S. Y.; Langmuir 2008, 24, 239

72. Julian-Lopez, B.; Boissiere, C.; Chaneac, C.; Grosso, D.; Vasseur, S.; Miraux, S.; Duguet, E.; Sanchez, C.; J. Mater. Chem. 2007, 17, 1563.

73. Souza, K. C.; Mohallem, N. D. S.; Sousa, E. M. B.; J. Sol-Gel Sci. Technol. 2010, 53, 418.

74. Brilley-Saebo, K.; Bjornerud, A.; Grant, D.; Ahlstrom, H.; Berg, T.; Kindberg, G. M.; Cell Tissue Res 2004, 316, 315.

75. Lunov, O.; Syrovets, T.; Röcker, C.; Tron, K.; Nienhaus, G. U.; Rasche, V.; Mailänder, V.; Landfester, K.; Simmet, T.; Biomaterials 2010, 31, 9015.

76. Lévy, M.; Lagarde, F.; Maraloiu, V. A.; Blanchin, M. G.; Gendron, F.; Wilhelm, C.; Gazeau, F.; Nanotechnology 2010, 21, 395103.

77. Beard, J. L.; Dawson, H.; Pinero, D. J.; Nutr Rev. 1996, 54, 295.

78. Kunzmann, A.; Andersson, B.; Thurnherr, T.; Krug, H.; Scheynius, A.; Fadeel, B.; Biochim. Biophys. Acta 2011, 1810, 361.

79. Raynal, I.; Prigent, P.; Peyramaure, S.; Najid, A.; Rebuzzi, C.; Corot, C.; Invest. Radiol. 2004, 39, 56.

80. He, Q.; Shi, J.; Zhu, M.; Chen, Y.; Chen, F.; Microporous Mesoporous Mater. 2010, 131, 314.

81. Hudson, S. P.; Padera, R. F.; Langer, R.; Kohane, D. S.; Biomaterials 2008, 29, 4045 .

82. He, Q.; Zhang, Z.; Gao, F.; Li, Y.; Shi, J.; Small 2011, 7, 271.

83. Li, X.; Zhang, L.; Dong, X.; Liang, J.; Shi, J.; Microporous Mesoporous Mater. 2007, 102, 151.

84. Viitala, R.; Jokinen, M.; Rosenholm, J. B.; Int. J. Pharm. 2007, 336, 382.

85. Vallhov, H.; Gabrielsson, S.; Stromme, M.; Scheynius, A.; GarciaBennett, A. E.; Nano Lett. 2007, 7, 3576.

86. Chung, T. H.; Wu, S. H.; Yao, M.; Lu, C. W.; Lin, Y. S.; Hung, Y.; Mou, C. Y.; Chen, Y. C.; Huang, D. M.; Biomaterials 2007, 28, 2959.

87. Tao, Z.; Toms, B. B.; Goodsman, J.; Asefa, T.; Chem. Res. Toxicol. 2009, $22,1869$.

88. He, Q.; Zhang, Z.; Gao, Y.; Shi, J.; Li, Y.; Small 2009, 5, 2722. 